6

\title{
Physico-chemical, antimicrobial and antioxidant properties of gelatin-chitosan based films loaded with nanoemulsions encapsulating active compounds
}

\author{
Luis J. Pérez-Córdoba ${ }^{\mathrm{a}, \mathrm{b} *}$, Ian T. Norton ${ }^{\mathrm{b}}$, Hannah K. Batchelor ${ }^{\mathrm{c}}$, Konstantinos Gkatzionis ${ }^{\mathrm{b}}$, Fotios \\ Spyropoulos $^{\mathrm{b}}$, Paulo J.A. Sobral ${ }^{\mathrm{a}}$
}

${ }^{a}$ Department of Food Engineering, Faculty of Animal Science and Food Engineering, University of São Paulo, Pirassununga 13635-900, São Paulo, Brazil. *E-mail: luchop283@usp.br.

${ }^{\mathrm{b}}$ School of Chemical Engineering, University of Birmingham, Edgbaston, Birmingham B15 2TT, UK ${ }^{\mathrm{c}}$ Pharmacy School, University of Birmingham, Edgbaston, Birmingham B15 2TT, UK

\section{Abstract}

The aim of this research was to develop and characterize gelatin-chitosan (4:1) based films that incorporate nanoemulsions loaded with a range of active compounds; $\mathrm{N}_{1}$ : canola oil; $\mathrm{N}_{2}$ : $\alpha$ tocopherol/cinnamaldehyde; $\mathrm{N}_{3}$ : $\alpha$-tocopherol/garlic oil; or $\mathrm{N}_{4}$ : a-tocopherol/cinnamaldehyde and garlic oil. Nanoemulsions were prepared in a microfluidizer with pressures ranging from 69 to $100 \mathrm{MPa}$, and 3 processing cycles. Films were produced by the casting method incorporating $5 \mathrm{~g} \mathrm{~N}_{1,2,3,4} / 100 \mathrm{~g}$ biopolymers and using glycerol as a plasticizer, and subsequently characterized in terms of their physico-chemical, antimicrobial and antioxidant properties. No differences ( $p>0.05)$ were observed for all films in terms of moisture content $(18 \% \mathrm{w} / \mathrm{w})$, and thermal properties. The films' solubility in water and light transmission at $280 \mathrm{~nm}$ were considerably reduced as compared to the control, $\mathrm{N}_{1}(15 \%$ and $60 \%$ respectively) because of the nanoemulsion incorporation. The film loaded with $\mathrm{N}_{1}$ showed the greatest $(\mathrm{p}<0.05)$ opacity, elongation at break and stiffness reduction, and was the roughest, whilst the lowest tensile strength and ability to swell were attained by films loaded with $\mathrm{N}_{3}$ and $\mathrm{N}_{4}$, respectively. DSC and X-ray analyses suggested compatibility among the biopolymeric-blend, and a good distribution of nanodroplets embedded into the matrix was confirmed by AFM and SEM analyses. Films loaded with nanoencapsulated active compounds (NAC) were very effective against Pseudomonas aeruginosa, and also showed high antioxidant activity. Overall, the present study offers clear evidence that these active-loaded films have the potential to be utilized as packaging material for enhancing food shelf life.

Keywords: biopolymer, active films, emulsion, $\alpha$-tocopherol, cinnamaldehyde, garlic oil.

\section{Chemical compounds studied in this article:}

Cinnamaldehyde (PubChem CID: 637511); alpha-tocopherol (PubChem CID: 14985); Garlic oil (PubChem CID: 6850738); Tween 20 (PubChem CID: 443314); Span 60 (PubChem CID: 14928); Chitosan (21896651); Acetic acid (PubChem CID: 176); Glycerol (PubChem CID: 753); 2,2'-azino- 
bis(3-ethylbenzothiazoline-6-sulphonic acid) (PubChem CID: 16240279); 1,1-Diphenyl-2picrylhydrazyl (PubChem CID: 2735032).

\section{Introduction}

The development of biodegradable packaging has been the focus of recent research, as an alternative to plastic material derived from petroleum, which due to their poor biodegradation generate a massive accumulation of plastic waste in the environment (Arancibia, Giménez, López-Caballero, Gómez-Guillén, \& Montero, 2014; Rubilar et al., 2013). Films based on biopolymers do not have the same physical properties as synthetic plastics, but they present a promising application because they generally are from renewable sources, non-toxic, biodegradable, biocompatible, and sometimes could become edible material (Chen et al., 2016; Kurek, Galus, \& Debeaufort, 2014; Pérez-Córdoba \& Sobral, 2017). Furthermore, these films are excellent vehicles for incorporating a wide variety of active agents, such as antioxidant and antimicrobial compounds, and thus, these biodegradable materials can be used for active packaging (Abdollahi, Rezaei, \& Farzi, 2012; Rhim \& Ng, 2007).

According to Gennadios, McHugh, Weller, \& Krochta (1994), gelatin (G) was one of the first materials used as a carrier of bioactive components. Gelatin is a protein obtained by hydrolyses of the collagen from bones and skin via exposure to acidic (type-A) or alkaline (type-B) pre-treatment conditions (Gómez-Guillén et al., 2009). Gelatin has excellent film-forming properties and can generally form films with good mechanical characteristics that also act as barriers to oxygen, carbon dioxide, and volatile compounds (Tongnuanchan, Benjakul, \& Prodpran, 2012); they form however a relatively poor barrier to moisture mainly due to the hydrophilic nature of the gelatin molecules (Ahmad et al., 2012). Moreover, gelatin has the ability to blend well with others biopolymers, such as chitosan (Bonilla \& Sobral, 2016; Pérez-Córdoba \& Sobral, 2017).

Chitosan $(\mathrm{Ch})$ is a linear polysaccharide consisting of $\beta$-(1-4)-2-acetamido-D-glucose and $\beta$ (1-4)-2-amino-D-glucose units, derived from chitin through deacetylation in alkaline media, and it is the second most abundant polysaccharide found in nature, after cellulose (Baron, Pérez, Salcedo, PérezCórdoba, \& Sobral, 2017; Elsabee \& Abdou, 2013). Similar to gelatin, chitosan has excellent filmforming properties and offers great potential as the basis for active packaging material due to its intrinsic antimicrobial activity (Kanatt, Rao, Chawla, \& Sharma, 2012). Blending chitosan with gelatin can produce films with improved properties, showing antimicrobial or antioxidant activity due to the presence of chitosan, or following the incorporation of hydrophilic bioactive agents (Benbettaïeb, Kurek, Bornaz, \& Debeaufort, 2014; Bonilla \& Sobral, 2016; Hosseini, Rezaei, Zandi, \& Ghavi, 2013; Jridi et al., 2014; Pereda, Ponce, Marcovich, Ruseckaite, \& Martucci, 2011; Rivero, García, \& Pinotti, 2009).

More recently, a number of studies have reported biopolymer films loaded with lipophilic compounds that are dispersed within the hydrophilic film structure as nanodroplets (nanoemulsions) 
Bittante, Moraes, \& Sobral, 2016; Chen et al., 2016; Otoni, Avena-Bustillos, Olsen, Bilbao-Sáinz, \& McHugh, 2016; Sasaki, Mattoso, \& de Moura, 2016). In parallel to these studies, other works have focused on the encapsulation of essential oils within a nanoemulsion microstructure (Sasaki et al., 2016), flavonoids, such as rutin (Dammak \& Sobral, 2017), curcumin (Sari et al., 2014) and other compounds like $\alpha$-tocopherol (Cheong, Tan, Man, \& Misran, 2008; Yang \& McClements, 2013), cinnamaldehyde (Donsì, Annunziata, Vincensi, \& Ferrari, 2012) or garlic oil (Wang, Cao, Sun, \& Wang, 2011). Potential applications of nanoemulsions for the encapsulation of bioactive components, either as a viable and efficient approach to increase their physical stability or in order to minimize their potentially detrimental sensorial effects, have been well documented within the food sciences research arena (Donsì, Annunziata, Sessa, \& Ferrari, 2011; Fathi, Mozafari, \& Mohebbi, 2012).

Among such bioactive compounds recently studied, $\alpha$-tocopherol $(\alpha-\mathrm{t})$, cinnamaldehyde (Cin), and garlic oil (GO) have been shown to exhibit a wide range of biological effects including antimicrobial and/or antioxidant properties (Donsì et al., 2012; Wang et al., 2011; Yang \& McClements, 2013). $\alpha$-tocopherol is an isomer and the most naturally abundant and biologically active form of vitamin $\mathrm{E}$ in humans (Yang \& McClements, 2013) and it has been shown to have high antioxidant activity in both biological and food systems (Saberi, Fang, \& McClements, 2013). Cinnamaldehyde is a hydrophobic aromatic compound with a benzene ring and an aldehyde group. It is the main active component of cinnamon oil (Chen et al., 2016) and it has been shown to be active against a broad range of foodborne pathogens bacteria, fungi and viruses (Wei, Xiong, Jiang, Zhang, \& Wen Ye, 2011). Garlic oil is an essential oil extracted from garlic bulbs, which contains a range of compounds; mainly diallyl disulfide (60\%), diallyl trisulfide (20\%), allyl propyl disulfide (16\%), a small quantity of disulfide and possibly diallyl polysulfide (Pranoto, Rakshit, \& Salokhe, 2005). It is also used as a food preservative and it has been shown to inhibit the growth of a wide range of pathogens and spoilage microorganisms, including bacteria, mold, fungi, parasites and viruses (Sung, Sin, Tee, Bee, \& Rahmat, 2014). All three of these active compounds have been categorized as safe (GRAS) for use in food by the US Food and Drug Administration (FDA) (Chen et al., 2016; Wei et al., 2011) and have been independently used as active additives within a range of packaging formulations (Noronha, De Carvalho, Lino, \& Barreto, 2014; Otoni et al., 2016; Pranoto et al., 2005). However, they are poorly soluble in water and as such extremely difficult to incorporate within film formulations, which are usually hydrophilic/aqueous systems (Alexandre et al., 2016).

The present study reports on a microstructural approach that involves the encapsulation of active compounds within oil-in-water $(\mathrm{O} / \mathrm{W})$ nanoemulsions, before incorporating these into a biopolymer film formulation, in order to facilitate dispersion of the bioactive species into the biopolymer matrix (Chen et al., 2016). To the best of the authors' knowledge, the joint incorporation of nanoencapsulated active compounds (NAC), such as $\alpha$-t, plus Cin and/or GO, within gelatin-chitosan (G-Ch) based films, in order to improve the films' physicochemical, antimicrobial and antioxidant properties, has not been previously reported. The objective of this work was to successfully produce G- 
111 Ch based films loaded with O/W nanoemulsions containing the encapsulated $\alpha$-t, and Cin and/or GO 112 active compounds and then characterize these formulations in terms of moisture content, solubility in 113 water, swelling, light transmission, opacity, crystallinity, mechanical and thermal properties, 114 microstructure, as well as their antioxidant and antimicrobial activities, thus enabling future development and application of such composite systems as food packaging material.

\section{Material and Methods}

\subsection{Material}

Garlic oil (purity $>99 \%$ ), cinnamaldehyde ( $>95 \%$ ), and $\alpha$-tocopherol (>96\%), Span 60, medium molecular weight chitosan (degree of deacetylation: 75-85\% and viscosity: 200-800 cps), Trolox, TPTZ (2,4,6-tripyridyl-s-triazine), chloride acid, Iron trichloride, and ethanol were purchased from Sigma-Aldrich and Labsynth (São Paulo, Brazil). Pigskin gelatin (type A, bloom $260^{\circ}$ and molecular weight $\sim 5.2 \times 10^{4}$ Da) was supplied by GELNEX (Itá, SC, Brazil). Acetic acid, glycerol, Tween 20, DPPH (2,2-diphenyl1-picrylhydrazyl), potassium persulfate, $\mathrm{ABTS}^{\bullet+}$ [2,2'-azino-bis(3-ethylbenzothiazoline-6-sulphonic acid)], sodium bromide, sodium hydroxide, nutrient broth, and Mueller Hinton agar were obtained from Sigma-Aldrich (Dorset, England, UK). Canola oil was purchased from a local supermarket. Deionized Millipore water (Elix ${ }^{\circledR} 5 \mathrm{UV}$, essential), tetracycline, and strains of bacteria P. aeruginosa (ATCC 15692) and L. monocytogenes (ATCC 35152) were provided by the microbiology laboratory at the

\subsection{Nanoemulsion preparation}

The $\alpha$-tocopherol and cinnamaldehyde and/or garlic oil were encapsulated in nanoemulsions using the microfluidization technique. Three oil-in-water $(\mathrm{O} / \mathrm{W})$ nanoemulsions containing a fixed amount of $3 \%(\mathrm{w} / \mathrm{v}) \alpha-\mathrm{t} / \mathrm{Cin}\left(\mathrm{N}_{2}\right), \alpha-\mathrm{t} / \mathrm{GO}\left(\mathrm{N}_{3}\right)$, or an equimolar mixture of $\alpha$-t/Cin and GO $\left(\mathrm{N}_{4}\right)$ were prepared by firstly incorporating these active compounds into canola oil, using Span 60 (1.5 w/v) as the lipophilic emulsifier. This oil phase $(10 \% \mathrm{w} / \mathrm{v})$ was then initially mixed with an aqueous phase containing water and Tween $20(3.5 \% \mathrm{w} / \mathrm{v})$ as the hydrophilic emulsifier in a 1:9 ratio using a magnetic stirrer (RH basic2, IKA, Germany) for 5 min at room temperature. Afterwards, a coarse emulsion was prepared using a high shear mixer (Silverson L5M, Buckinghamshire, UK) operating at $5000 \mathrm{rpm}$ for 5 min. These coarse emulsions were analyzed by optical microscopy (DFC 450C, Leica, Germany). Nanoemulsions were obtained by passing the coarse emulsion through a microfluidizer (M-110S, Microfluidics, USA) at different pressures (69-100 MPa) and 3 processing cycles, selected after previous optimization (data not shown).

An O/W nanoemulsion with the same oil:aqueous phase (1:9) ratio, without active compounds, was prepared following the same procedure, and it was considered as a control $\left(\mathrm{N}_{1}\right)$. Samples were stored in amber glass containers at $4 \pm 1{ }^{\circ} \mathrm{C}$ and their stability was monitored over a period of 90 days. 
The encapsulation efficiency (EE) of all active species within the nanoemulsions was calculated immediately post-emulsification and after 90 days of storage (Equation 1).

$$
E E=\left(A C_{R} / A C_{I}\right) \times 100
$$

150

151

152

153

154

155

156

157

158

159

160

161

162

163

164

165

166

167

168

169

170

171

172

173

174

175

176

177

178

179

180

181

where $A C_{R}$ is the amount of active compound ( $\alpha-\mathrm{t}$, Cin or GO) remaining within the droplets of the nanoemulsion, determined as described below, and $A C_{I}$ is the amount of active compound initially added to the emulsion (Davidov-Pardo \& McClements, 2015).

The amount of active compound ( $\alpha$-t, Cin or GO) remaining within the droplets of the nanoemulsion was determined by using an $\mathrm{UHPLC}^{+}$(Dionex Ultimate 3000, Thermo scientific, Germany). Analyses were carried out by diluting the sample in methanol to facilitate the $\alpha$-tocopherol and garlic oil $(0.01 \% \mathrm{v} / \mathrm{v})$ or cinnamaldehyde $(0,003 \% \mathrm{v} / \mathrm{v})$ detection. The diluted samples were separated in a Phenomenex Luna 3a C18 column $(150$ x 4.6 mm, i.d. $3 \mu \mathrm{m})$ with an elution system of methanol:acetonitrile:water (68:28:4) for $\alpha$-tocopherol or methanol:acetonitrile:phosphoric acid (1\% v/v) (50:30:20) for cinnamaldehyde and garlic oil. The flow rate of the mobile phase solvents was 1 $\mathrm{mL} / \mathrm{min}$, the injection volume was $25 \mu \mathrm{L}$ ( $\alpha$-t) or $10 \mu \mathrm{L}$ (Cin and GO), and the detection wavelength was set at 208, 285 and $210 \mathrm{~nm}$, for $\alpha$-t, Cin and GO respectively (Mao, Yang, Xu, Yuan, \& Gao, 2010).

The nanoemulsions were characterized in terms of their mean particle size, polydispersity index, and $\zeta$-potential using a Zetasizer (Nanoseries, Malvern Instruments, UK), $\mathrm{pH}$ using a pHmeter (SevenCompact, Mettler Toledo, Switzerland), flow behavior using a rheometer (Kinexus Pro ${ }^{+}$, Malvern Instruments, UK), and microstructure and morphology using atomic force microscopy (Ntegra prima, NT-MDT Co., Russia). All measurements were performed at least in triplicate. These characterized nanoemulsions $\left(\mathrm{N}_{1}, \mathrm{~N}_{2}, \mathrm{~N}_{3}\right.$, and $\left.\mathrm{N}_{4}\right)$ were then incorporated within the fabricated $\mathrm{G}-\mathrm{Ch}$ based films.

\subsection{Film production}

Films were produced by blending G-Ch (4:1 ratio) using the casting technique. A film-forming solution (FFS) (5 g biopolymer/100 g FFS), loaded with nanoemulsions encapsulating active compounds ( $5 \mathrm{~g} / 100 \mathrm{~g}$ biopolymer) and glycerol (30 g/100 g biopolymer) as the plasticizer, was used. Gelatin and chitosan solutions loaded with nanoemulsions were prepared separately, then, the FFS was mixed under stirring in a plate stirrer (SB162-3, Stuart, UK) for $10 \mathrm{~min}$, and subsequently homogenized using a high shear mixer (Silverson L5M, Buckinghamshire, UK) at $5000 \mathrm{rpm}$ for $5 \mathrm{~min}$. During stirring, the $\mathrm{pH}$ was adjusted at 5.6 for complexation between chitosan and gelatin to take place; the selected $\mathrm{pH}$ value is above the isoelectric point of gelatin $(P i=4.5-5.2)$, where all the gelatin chains are negatively charged, and below $\mathrm{pH} 6.2$ in order to prevent chitosan precipitating out of solution (Benbettaïeb et al., 2014). FFS was sonicated and degassed in a Sonicator (ultrasonic cleaner QS18, Ultrawave, UK) at $50^{\circ} \mathrm{C}$ for $10 \mathrm{~min}$. Finally, FFS was poured into a plastic Petri dish (14 cm diameter) 
and placed in a forced air oven (GPS/50/CLAD/250/HYD, Leader, UK) at $30 \pm 0.5^{\circ} \mathrm{C}$ for $24 \mathrm{~h}$, in order to obtain the films.

After peeling from the petri dish, the films were conditioned inside desiccators containing a saturated solution of $\mathrm{NaBr}$ (relative humidity 58\%) for 7 days, prior to the characterization of their physicochemical, antimicrobial, and antioxidant properties. For SEM and AFM analyses, the newly formed films were instead conditioned in silica gel (relative humidity $0 \%$ ) for the same period. Furthermore, two films were made using the same G-Ch blend (4:1). The first one was prepared without the incorporation of a nanoemulsion $\left(\mathrm{N}_{0}\right)$, while the second one was loaded with a control nanoemulsion $\left(\mathrm{N}_{1}\right)$ described in section 2.2. Both films were formed using glycerol as a plasticizer and they were produced and conditioned as described above; hereinafter referred to as control 1 and control 2 films, respectively.

\subsection{Film Characterization}

\subsubsection{Thickness}

A digital micrometer (AK9635D, Sealey, UK) was used to measure the film thickness to the nearest $0.001 \mathrm{~mm}$ at 10 random positions on the surface of each film produced (Barón et al. 2017).

\subsubsection{Moisture content}

Moisture content (MC) was determined by cutting film samples into discs (20 $\mathrm{mm}$ in diameter) and measuring the reduction in the mass of a minimum of 3 discs (from each film) following oven drying (GPS/50/CLAD/250/HYD, Leader, UK) at $105^{\circ} \mathrm{C}$ for $24 \mathrm{~h}$. The results were expressed as $\mathrm{g}$ of water/100 g of wet material (Barón et al. 2017). Measurements were performed in triplicate.

\subsubsection{Solubility in water and swelling}

For solubility in water (SW) and swelling (S) measurements, film samples were cut in discs (20 $\mathrm{mm}$ in diameter), weighed, and immersed in $50 \mathrm{~mL}$ of distilled water under stirring in a shaker (IncuShake MIDI, SciQuip, UK) at $60 \mathrm{rpm}$ and at room temperature for $24 \mathrm{~h}$. Film samples were then removed from the solution, re-weighed, and dried in an oven at $105^{\circ} \mathrm{C}$ for $24 \mathrm{~h}$ to determine their final dry matter. These values were then used to calculate SW and S, expressed as $\mathrm{g}$ of solubilized mass/100 $\mathrm{g}$ of dried material and $\mathrm{g}$ of gained water/g of dried material, respectively (Gontard et al. 1994). All measurements were carried out in triplicate.

\subsubsection{Mechanical properties}

Tensile strength (TS), elongation at break (EB), and elastic modulus (EM) were measured according to the ASTMD 882/12 standard method (2001). Samples were cut into $15 \mathrm{~mm}$ x $100 \mathrm{~mm}$ strips, and tested using a texture analyzer (TA.XT2i, Stable Micro System, UK) with grip separation of $50 \mathrm{~mm}$ and speed rate of $1 \mathrm{~mm} / \mathrm{s}$ until breaking. TS and EB were obtained directly from the stress $v s$. 
strain curves, which are produced from the force-deformation data, and the EM was determined as the angular coefficient in the linear part of the curve using the Exponent Lite v.4.0.13.0 software (Stable Micro System, UK) (Baron et al., 2017). Data were collected for at least 10 sample strips from each film.

\subsubsection{Light transmission and transparency}

Light transmission of films against ultraviolet and visible light was determined in transmittance mode at selected wavelengths (200 to $800 \mathrm{~nm}$ ) using a UV-VIS spectrophotometer (Orion AquaMate 8000, Thermo Scientific, Germany), according to the procedure described by Bonilla \& Sobral (2016). The transparency value for each film was calculated using Equation 2.

$$
\text { Transparency value }=\left(-\log \mathrm{T}_{600}\right) / \mathrm{x}
$$

where $\mathrm{T}_{600}$ is the fractional transmittance at $600 \mathrm{~nm}$, and $\mathrm{x}$ is the film thickness $(\mathrm{mm})$. The higher transparency value represents the lower transparency of films (Ahmad et al., 2012). Five samples of each film were used for transmittance measurements.

\subsubsection{X-ray diffraction (XRD)}

XRD was used to determine the film's crystallinity. Analyses were carried out using an X-ray diffractometer (Miniflex600, Rigaku, Japan) with $\mathrm{Cu}$ as the source. Samples were cut in squares of 20 $\mathrm{mm} \times 20 \mathrm{~mm}$ and placed on a glass plate, which was placed inside the chamber of the equipment. Measurements were recorded in triplicate at room temperature, $40 \mathrm{kV}$ and $40 \mathrm{~mA}$ current, in the region of $2 \theta$ from $8^{\circ}$ to $70^{\circ}$ (with a constant speed of $1^{\circ} \mathrm{min}^{-1}$ ) using the Miniflex Guidance software (Rigaku, Japan) (Chen et al., 2016).

\subsubsection{Differential scanning calorimetry (DSC)}

Thermal properties of the films were determined using a differential scanning calorimeter (DSC TA2010, TA Instruments, USA), controlled by a TA5000 system (TA Instruments, USA) and a quench cooling accessory. Approximately $10 \mathrm{mg}( \pm 0.01 \mathrm{mg})$ of sample were weighed in a precision balance (AP 2500 Analytical Plus, Ohaus, Switzerland), were conditioned in a hermetically sealed aluminum pan and heated in double run at $5^{\circ} \mathrm{C} / \mathrm{min}$ from -150 to $150{ }^{\circ} \mathrm{C}$ in an inert atmosphere $\left(45 \mathrm{ml} / \mathrm{min}\right.$ of $\left.\mathrm{N}_{2}\right)$. An empty pan was used as the control. The results were analyzed using the instrument's software (V1.7F, TA Instruments, USA) in order to determine the glass transition temperature (Tg), in the first and second scan, as well as the melting temperature $(\mathrm{Tm})$ and enthalpy $(\Delta \mathrm{Hm})$ of the sol-gel transition (Alexandre et al., 2016; Sobral, Menegalli, Hubinger, \& Roques, 2001). DSC measurements were performed in triplicate. 


\subsubsection{Atomic force microscopy (AFM)}

AFM analyses were performed according to Ma et al. (2012), using the atomic force microscope (Topview optics ${ }^{\mathrm{TM}}$ Nanowizard, JPK Instruments, Germany) equipped with a DP17/GP/NAl $(\mu \mathrm{MASCH})$ tip and operated in contact mode. Samples $(2 \mathrm{~cm} \times 2 \mathrm{~cm})$ from each film were pasted on a glass slice using a double-sided adhesive tape. AFM images (with a scan size of $10 \mu \mathrm{m} \times 10 \mu \mathrm{m}$ ) were collected from the air side of the films at a fixed scan rate of $0.7-0.8 \mathrm{~Hz}$. The surface roughness of the films was calculated based on the root mean square (RMS) deviation from the average height of peaks after subtracting the background using the JPK-SPM and JPK Data processing software (JPK, Germany) (Ma et al., 2012).

\subsubsection{Scanning electron microscopy (SEM)}

Film microstructures were studied using an environmental scanning electron microscope (FEGESEM XL30, Phillips, Japan). Film samples were fixed on the support using double-sided adhesive tape and initially coated with Platinum in a Sputter coater (SC7640, Quorum Technologies, UK) to allow better observation of film surface and cross section. Micrographs of the films' surfaces and crosssections were taken in triplicate at random positions on the films, at $10 \mathrm{kV}$ and a magnification of $1000 \mathrm{x}$. For cross-sectional analysis, samples were cryo-fractured after immersion in liquid nitrogen (Kurek et al., 2014).

\subsubsection{Antimicrobial activity}

The antimicrobial activity of the films was assessed against Pseudomonas aeruginosa ATCC 15692 and Listeria monocytogenes ATCC 35152 by the agar diffusion method based on the guidelines of the Clinical and Laboratory Standards Institute (CLSI, 2006) with slight modifications (Wayne, 2006). Microbial cultures were grown overnight in nutrient broth (Sigma Aldrich, England, UK) at 37 ${ }^{\circ} \mathrm{C}$ and $150 \mathrm{rpm}$. The cells were harvested by centrifugation at $2000 \mathrm{rpm}$ for $10 \mathrm{~min}$ and washed in sterile phosphate buffer saline (pH 7.2) twice (Kadri, Devanthi, Overton, \& Gkatzionis, 2017). Inocula with a turbidity equivalent to a McFarland 0.5 standard were prepared $\left(10^{8} \mathrm{cfu} / \mathrm{mL}\right)$, then diluted to a final concentration of $10^{5} \mathrm{cfu} / \mathrm{mL}$ into Mueller Hinton agar (Merck, UK) and poured into petri plates after mixing (Kavoosi, Rahmatollahi, Mohammad Mahdi Dadfar, \& Mohammadi Purfard, 2014). After solidification, discs (diameter $20 \mathrm{~mm}$ ) of films containing the nanoemulsions $\mathrm{N}_{1}, \mathrm{~N}_{2}, \mathrm{~N}_{3}$ and $\mathrm{N}_{4}$ (or not, $\mathrm{N}_{0}$ ), were placed in plicate on the medium, and the plates were incubated at $37^{\circ} \mathrm{C}$ for $24 \mathrm{~h}$. The area of the whole zone was calculated, then subtracted from the film disc area, and this difference in area was reported as the zone of inhibition (Seydim \& Sarikus, 2006).

\subsubsection{Determination of antioxidant activity}

The films' antioxidant activity was measured using the 2,2'-azino-bis(3-ethylbenzothiazoline6-sulphonic acid) $\left(\mathrm{ABTS}^{\bullet+}\right)$ and 1,1-diphenyl-2-picrylhydrazyl (DPPH$\left.{ }^{\bullet}\right)$ free radical scavenging 
methods, and the ferric reducing ability of plasma (FRAP) assay, as described by Re et al. (1999), Brand-Williams, Cuvelier, \& Berset (1995) and Ferreira, Nunes, Castro, Ferreira, \& Coimbra (2014), respectively. For $\mathrm{ABTS}^{\bullet+}$ and $\mathrm{DPPH}^{\bullet}$ analyses, $0.1 \mathrm{~g}$ samples from each film were immersed into $10 \mathrm{ml}$ of a hydroalcoholic mixture (1:1) and kept under agitation overnight at $80 \mathrm{rpm}$ and $20^{\circ} \mathrm{C}$ to encourage the extraction of the encapsulated compounds. All antioxidant analyses were performed in triplicate.

\subsubsection{ABTS $^{\bullet+}$ method.}

A solution containing ABTS $^{\bullet+}$ radical $(7 \mathrm{mM})$ and potassium persulfate $(2.45 \mathrm{mM})$ was initially mixed (1:0.5) and kept in the dark for $16 \mathrm{~h}$. Subsequently, an aliquot of this solution was diluted with ethanol in order to prepare the $\mathrm{ABTS}^{\bullet+}$ working solution with an absorbance value of $0.70 \pm 0.02$, as measured using a UV-Vis spectrophotometer at $734 \mathrm{~nm}$. An aliquot $(100 \mu \mathrm{L})$ of the solubilized and centrifuged (4000 rpm, $30 \mathrm{~min}$ ) samples was added to the $\mathrm{ABTS}^{\bullet+}$ working solution $(900 \mu \mathrm{L})$, and the mixture was kept in the dark within 6 min (Bonilla \& Sobral, 2016; Re et al., 1999). Antioxidant activity is calculated and expressed as Trolox equivalent TE ( $\mu \mathrm{mol} / \mathrm{g}$ dried film).

\subsubsection{DPPH• method.}

A centrifuged (4000 rpm, $30 \mathrm{~min})$ aliquot of the solubilized film $(1.5 \mathrm{~mL})$ was added to $1.5 \mathrm{~mL}$ of $\mathrm{DPPH}^{\bullet}$ radical solution $(60 \mu \mathrm{M})$, and it was kept in the dark for one hour. After this period, the absorbance was determined at $515 \mathrm{~nm}$ using a UV-Vis spectrophotometer (Brand-Williams et al., 1995). Antioxidant activity is calculated and expressed as Trolox equivalent TE ( $\mu \mathrm{mol} / \mathrm{g}$ dried film). Antioxidant activity is expressed as TE $(\mu \mathrm{mol} / \mathrm{g}$ dried film).

\subsubsection{FRAP assay}

A solution of $\mathrm{FeCl}_{3}(20 \mathrm{mM})$ was prepared in distilled water and TPTZ was prepared in $40 \mathrm{mM}$ $\mathrm{HCl}$. To prepare the FRAP reagent, $25 \mathrm{~mL}$ acetate buffer $(0.3 \mathrm{M}, \mathrm{pH} 3.6)$ were mixed with $2.5 \mathrm{~mL}$ of TPTZ and $2.5 \mathrm{~mL} \mathrm{FeCl}_{3}$. Film samples of $50 \mathrm{~mm}$ x $50 \mathrm{~mm}(\sim 2.5 \mathrm{mg})$ were placed in $3 \mathrm{~mL}$ of FRAP solution and $0.3 \mathrm{~mL}$ of distilled water for $24 \mathrm{~h}$. Following this period, the absorbance of the filmcontaining solution was measured at $593 \mathrm{~nm}$ using a UV-Vis spectrophotometer. The absorbance of the FRAP solution (without the film) was also measured as a blank (Ferreira et al., 2014). Antioxidant activity is expressed as TE ( $\mu \mathrm{mol} / \mathrm{g}$ dried film).

\subsection{Statistical analysis}

Analysis of variance (ANOVA) was conducted using the Statgraphics ${ }^{\circledR}$ centurion XV (StatPoint, Inc., 2006) software. The obtained mean values were subjected to Duncan's multiple-range test, and in all cases, values with $\mathrm{p}<0.05$ were considered to be significant. 


\subsection{Nanoemulsion characterization}

\subsubsection{Encapsulation efficiency}

The results presented in Table 1 show that Cin and GO had higher EE than $\alpha$-t during the encapsulation process and nanoemulsion storage. Nevertheless, all of them had a slight reduction in EE during storage. This loss could be associated with the high pressure and cycle number used in the nanoemulsion preparation or could be due to the partial volatility of those compounds, principally the Cin and GO. Furthermore, the harsh processing conditions, as well as the presence of heat, light, and oxygen during processing, could explain the active compound loss. These extreme conditions might have caused chemical degradation of $\alpha$-tocopherol, resulting in a reduction of the quantified $\alpha-t$ concentration (Anarjan, Mirhosseini, Baharin, \& Tan, 2011; Cheong et al., 2008). When comparing the EE for Cin or GO between $\mathrm{N}_{2}$ or $\mathrm{N}_{3}$ and $\mathrm{N}_{4}$, which contain the three joint mixed compounds (Table 1), a clear reduction in the encapsulated compound quantified immediately post-emulsification and also a significant difference $(p<0.05)$ between the EE values after 90 days of storage for both Cin and GO was seen. Hence, the fact that encapsulating three compounds instead of two, clearly affected their EE. On the other hand, the EE for $\alpha$-t did not show significant difference ( $p>0.05)$ after post-emulsification regardless of the nanoemulsion. However the storage time had a significant $(\mathrm{p}<0.05)$ effect on the EE for this active compound in all nanoemulsions, which was expected due to the high sensitivity of this molecule (Nhan \& Hoa, 2013).

Despite the obtained EE during the nanoemulsion preparation and the slight loss of the active compounds after 90 days under refrigeration, it was proven that the remaining NAC was sufficient to guarantee a very good antimicrobial and antioxidant properties for the prepared emulsions (data not shown.

\subsubsection{Droplet size, polydispersity, $\zeta$-potential and pH measurements}

The nanoemulsions were also evaluated in terms of their physicochemical properties (Table 1). The control nanoemulsion $\left(\mathrm{N}_{1}\right)$ without encapsulated actives, presented the highest $(\mathrm{p}<0.05)$ droplet size, polydispersity index (PDI), $\zeta$-potential, and $\mathrm{pH}$ values, among all tested formulations (Table 1 ). For nanoemulsions loaded with active compounds, mean particle size, PDI, and $\zeta$-potential values remained between 111.0 and $130.0 \mathrm{~nm}, 0.14-0.20$ and -12.0 to $-16.0 \mathrm{mV}$, respectively, with all characteristics remaining unchanged over the 90 days storage (Table 1). All emulsions were found to possess droplet sizes within the desired nano-scale region with a monomodal size distribution (Figure across the 90-day storage at $4{ }^{\circ} \mathrm{C}$. 
The nanoemulsions were also analyzed using an atomic force (AFM) microscope. The size, homogeneity and spherical morphology of the oil nanodroplets were confirmed by the AFM data and images, which revealed uniformly sized spherical particles with sizes from 110 to $150 \mathrm{~nm}$ for all nanoemulsions (Figure 2), as measured by the dynamic light scattering (DLS) in Zetasizer (Table 1).

\section{Insert Table 1}

Insert Figure 1

Insert Figure 2

With regard to their polydispersity, only nanoemulsions with encapsulated active compounds had PDI values lower than 0.20 over the 90 -days storage (Table 1 ), displaying a monodisperse droplet size distribution (Figure 1) and showing a visual and physical stability, perhaps as a result of the optimal pressure and number of processing cycles used throughout the homogenization process, as reported in previous works by Tan \& Nakajima (2005); Troncoso, Aguilera, \& McClements (2012), and PérezCórdoba \& Sobral, (2017). Although the PDI value for the control nanoemulsions was 0.20 upon formation, this shifted slightly to higher values as a small shoulder at size ranges of approximately $8 \mu \mathrm{m}$ developed during storage (Figure 1a). These results suggested that the microfluidizer was able to produce nanoemulsions from coarse emulsions containing polydisperse micrometers droplets (Supplementary Figure S1). Nanoemulsions with $\zeta$-potential values greater than $+30 \mathrm{mV}$ or lower than $-30 \mathrm{mV}$ are expected to be highly stable since droplets are sufficiently charged to enable inter-particle repulsive forces to dominate (Heurtault, Saulnier, Pech, Proust, \& Benoit, 2003; Salvia-Trujillo, RojasGraü, Soliva-Fortuny, \& Martín-Belloso, 2013). As can be observed in Table 1, the negative $\zeta$-potential values for all nanoemulsions were above this $-30 \mathrm{mV}$ threshold, potentially as a result of the adsorption of hydroxyl ions at the oil-water interface and subsequent development of hydrogen bonds between these ions and the ethylene oxide groups of the surfactant (Dias et al., 2014; Jo \& Kwon, 2014). Nevertheless, despite their moderate magnitude, the resulting net charge differences in the tested nanoemulsions were able to contribute to the systems' high stability against creaming and/or flocculation phenomena during storage (Jo \& Kwon, 2014).

In terms of $\mathrm{pH}$, the control nanoemulsions were able to maintain a value of $\mathrm{pH} 6$ for the duration of storage, whilst a significant $(\mathrm{p}<0.05) \mathrm{pH}$ reduction was observed for all nanoemulsions with encapsulated active compounds. This behavior could be attributed to the production of acidic compounds (carboxylic acids) after the decomposition of hydroperoxides from the oxidation of the encapsulated lipophilic compounds (Cheong, Tan, \& Nyam, 2017; Grill, Ogle, \& Miller, 2006). Cheong et al., (2017) also observed the same $\mathrm{pH}$ reduction behavior and very close $\mathrm{pH}$ values for kenaf seed (Hibiscus cannabinus L.) oil-in-water nanoemulsion stored at $4{ }^{\circ} \mathrm{C}$. Hsu \& Nacu (2003) affirm that an ideal $\mathrm{pH}$ value for $\mathrm{O} / \mathrm{W}$ emulsions should be greater than 4.0 to ensure stability. Similarly, 
Nejadmansouri et al. (2016) reported that, at higher $\mathrm{pH}$ values $(\mathrm{pH}>4)$, nanoemulsions remain relatively stable against droplet aggregation as a result of sufficient electrostatic repulsions between negatively charged droplets (Nejadmansouri et al., 2016).

\subsubsection{Flow behavior of nanoemulsions}

In this study, the viscosity was not dependent on the shear rate used for the sample test when measured at ambient temperature $\left(20^{\circ} \mathrm{C} \pm 2^{\circ} \mathrm{C}\right)$. All prepared nanoemulsions presented viscosity values of approximately $10^{-3} \mathrm{mPa}$.s, being closer to the viscosity of water, and showed Newtonian behavior. This behavior could be attributed to that those nanoemulsions were prepared with an oil phase of $10 \%$ w/w. According to Floury, Desrumaux, Axelos, \& Legrand, (2003), emulsions containing less than 20\% (w/w) of the dispersed phase always show a Newtonian behavior, regardless of the homogenization pressure or another condition applied in their preparation. Alexandre et al. (2016) obtained similar flow behavior when preparing $\mathrm{O} / \mathrm{W}$ nanoemulsion loaded with ginger essential oil. This rheological behavior can be considered as interesting because water is the solvent usually used in the biopolymer-based film preparation (Alexandre et al. 2016).

\subsection{Film characterization}

Films prepared without $\left(\mathrm{N}_{0}\right)$ or with nanoemulsions $\left(\mathrm{N}_{1}, \mathrm{~N}_{2}, \mathrm{~N}_{3}\right.$, or $\left.\mathrm{N}_{4}\right)$ were visually homogeneous with no cracks, scratches, bubbles, or visible phase separation. Film thickness was well maintained by controlling the mass ratio of FFS/dish area and thus remained constant at $0.080 \pm 0.002$ $\mathrm{mm}$ ( $>0.05$ ) across all film formulations (Table 2). According to Benbettaïeb et al. (2014), controlling thickness is key for ensuring the films' physical and barrier properties.

\section{Insert Table 2}

\subsubsection{Moisture content, solubility in water and swelling}

No significant difference ( $p>0.05$ ) was observed in the moisture content (MC) of all samples (Table 2), which was maintained at approximately $18 \%$. It is therefore evident that the oil phase fraction in the nanoemulsions was relatively low and did not affect the hygroscopicity of the produced films, which was predominantly dictated by the biopolymer matrix (Pérez-Córdoba \& Sobral, 2017).

Solubility is another important film characteristic that can affect film integrity as well as the migration of the encapsulated bioactive compounds into the foodstuff (Mihaly Cozmuta et al., 2015). All films loaded with nanoemulsions $\left(\mathrm{N}_{1}, \mathrm{~N}_{2}, \mathrm{~N}_{3}\right.$, or $\mathrm{N}_{4}$ ) presented slightly lower $(\mathrm{p}<0.05)$ solubility in water (SW) than the control 1 film $\left(\mathrm{N}_{0}\right)$; SW values for the former were between 43.1 and $48.9 \%$, with films loaded with $\mathrm{N}_{2}$ and $\mathrm{N}_{3}$ exhibiting the lowest $\mathrm{SW}$ (p>0.05) (Table 2).

Ahmad et al. (2012) reported a reduction on the water solubility of gelatin-based films following the incorporation of bergamot and lemongrass oil. This was presumably due to the non-polar 
components in the used oils, which resulted in a substantial physical interference in the entanglement of gelatin polypeptide chains within the film matrix. Such interference, which might have led to a significant blockade on the capacity of gelatin to interact with water molecules, would be mainly responsible for reducing the water solubility of the composite films (Hosseini et al., 2013; Mihaly Cozmuta et al., 2015).

These SW values were similar to those reported by Ma et al. (2012) (44.7\%) and GómezEstaca, López de Lacey, López-Caballero, Gómez-Guillén, \& Montero (2010) (41.1\%) for gelatin or gelatin-chitosan based films loaded with nanoemulsified olive or clove oil droplets in water, respectively. This was attributed to the establishment of protein-polyphenol interactions which weaken the interactions that stabilize the protein network (Gómez-Estaca et al., 2010). On the other hand, Jridi et al. (2014) reported higher SW (85.6\%), and Benbettaïeb et al. (2014), Hosseini et al. (2013), and Gómez-Estaca et al. (2010) obtained lower SW values for G-Ch $(37.8-39.1 \%)$ or G-Ch films loaded with essential clove oil (29.5\%) than those obtained in this work. This evidence demonstrates that SW does not correspond to a simple rule of mixing and may result from interactions between both gelatin and chitosan caused by electrostatic forces, hydrogen bonding, etc, or by the presence of droplets oil that stabilize the film structure (Jridi et al., 2014; Pereda et al., 2011), as will be discussed in section 3.2.4 and seen in the X-ray diffractograms (Figure 3).

Despite its highest $\mathrm{SW}$, the control 1 film $\left(\mathrm{N}_{0}\right)$ displayed the lowest ability to swell $(26.9 \mathrm{~g} / \mathrm{g}$ ) as well as the greatest $(\mathrm{p}<0.05)$ surface hydrophobicity amongst all tested samples; the latter was evaluated by contact angle measurements (data not shown). Although film swelling (S) was found to vary between different systems $(\mathrm{p}<0.05)$, this was not dependent on the incorporation (or not) of the nanoemulsion, with the $\mathrm{N}_{1}$ and $\mathrm{N}_{4}$ films, displaying the highest $(30 \mathrm{~g} / \mathrm{g})$ and lowest $(25.3 \mathrm{~g} / \mathrm{g})$ swelling, respectively. Nonetheless it is expected that these films would exhibit a high degree of swelling due to the great water uptake capacity of gelatin and also the porous structure of its polymeric network (Kavoosi, Mohammad, Dadfar, Purfard, \& Mehrabi, 2013).

\subsubsection{Mechanical properties}

The $\mathrm{N}_{0}$ films displayed the highest $(\mathrm{p}<0.05)$ tensile strength (TS) and the lowest elongation at break (EB) values among all samples (Table 2); $19.0 \mathrm{MPa}$ and 89.1\%, respectively. In comparison to $\mathrm{N}_{0}$ films, films loaded with nanoemulsions showed a considerable reduction in TS, as well as an increase in their EB values, a typical behavior of plasticized films (Sobral et al., 2001). This is in agreement with previous studies reporting that addition of lipophilic species (e.g. essential oils or fatty acids) decreases the TS values of biopolymer-based films; e.g., films from gelatin (Limpisophon, Tanaka, \& Osako, 2010; Tongnuanchan, Benjakul, \& Prodpran, 2013), chitosan (Martins, Cerqueira, \& Vicente, 2012; Rubilar et al., 2013) or whey protein (Soazo, Rubiolo, \& Verdini, 2011), etc. This has been attributed to the inability of lipids to form continuous and cohesive matrices (Péroval, Debeaufort, Despré, \& Voilley, 2002; Rubilar et al., 2013). 
EB results obtained here are comparable to those reported by Kavoosi et al. (2013) and Tongnuanchan, Benjakul, \& Prodpran (2014) for gelatin based films; who obtained EB mean values of $128 \%$ and $114 \%$, respectively, and, similarly to the present study, a significant $(\mathrm{p}<0.05)$ decrease in TS when carvacrol, and basil or lemon essential oils were incorporated into the gelatin films. Similarly, Hosseini, Rezaei, Zandi, \& Farahmandghavi (2016) reported a significant ( $<<0.05)$ increase in EB value (reaching a maximum value of $151.8 \%$ ) for gelatin/chitosan based films emulsified with oregano oil $(0.4 \% \mathrm{w} / \mathrm{v})$ and also a reduction of $69 \%$ in its original tensile strength. This behavior has been attributed to the chemical nature of the films' biopolymeric components and the plasticizing role of the essential oil (loaded onto the matrix), resulting in the enhancement of their ductile properties (Hosseini et al., 2016; Tongnuanchan et al., 2012).

With regard to the EM results, the addition of nanoemulsions into the polymeric-blend matrix leads to a significant $(\mathrm{p}<0.05)$ reduction of the films' stiffness. The highest $(71.4 \%)$ and lowest $(61.3 \%)$ EM reduction was observed for $\mathrm{N}_{1}$ and $\mathrm{N}_{4}$ films, respectively (Table 2). Hosseini et al. (2016) also reported a significant $(\mathrm{p}<0.05)$ decrease on $\mathrm{EM}$ when different oregano oil concentrations were added into gelatin-chitosan based films. Similarly, Tongnuanchan et al. (2014) reported a significant $(p<0.05)$ reduction of EM for gelatin based films loaded with different essential oils (basil, plai and lemon), in respect to the control film (without essential oils).

\subsubsection{Light transmission and opacity}

Incorporation of the $\mathrm{N}_{1}$ nanoemulsion within the gelatin-chitosan film (control 2) significantly reduces the transmittance values in the wavelength range of 250 - $280 \mathrm{~nm}$ (Table 3) in comparison to those of $\mathrm{N}_{0}$ films (control 1). These transmittance values are then further reduced by the incorporation of $\alpha$-t, Cin, and/or GO within the nanodroplets, thus indicating that the formulated films act as excellent barriers to radiation in the ultraviolet (UV) light region when compared with both control films $\left(\mathrm{N}_{0}\right.$ and $\mathrm{N}_{1}$ ). In addition to the aromatic rings of amino acid residues from the gelatin molecule, this protective capacity of the films is envisaged to be enhanced by the chemical structure of the encapsulated compounds which contain phenolic groups (Bonilla \& Sobral, 2016; Dammak, Carvalho, Trindade, Lourenço, \& Sobral, 2017). Good UV and visible light barrier properties in the 200 - $350 \mathrm{~nm}$ range were also found by Gómez-Estaca, Giménez, Montero, \& Gómez-Guillén (2009) and Wu et al. (2013) in gelatin-based films containing oregano or green tea extracts, respectively. In the visible range (350 $800 \mathrm{~nm}$ ), the $\mathrm{N}_{0}$ films showed the highest ( $\mathrm{p}<0.05$ ) light transmission $(80-97 \%)$ when compared to films for gelatin-chitosan composite films (72.6-90.9\%) and higher than those reported by Dammak et al. (2017) for pure gelatin-based films (45-56\%). Hence, it can be seen that chitosan has a significant contribution in terms of light transmission in the visible range (Jridi et al., 2014).

\section{Insert Table 3}


On the other hand, the transparency of films differed significantly $(\mathrm{p}<0.05)$ among samples, when nanoemulsions were added, as evidenced in Table 3. This transparency values are directly associated with the film opacity (i.e, the $\mathrm{N}_{1}$ films presented the highest transparency value and the greatest opacity). In this case, the $\mathrm{N}_{0}$ films was the most transparent, however when adding the different nanoemulsions became opaque, maybe due to the nanoencapsulated active compounds (NAC), which were able to impede the light transmission through the films (Tongnuanchan et al., 2012) or due to the formation of poly-anion/cation complexes between the gelatin-chitosan matrix and the nanoemulsions (Jridi et al., 2014). Tongnuanchan et al. (2012) also reported that emulsified essential oil droplets incorporated into a gelatin based film lowered its transparency, likely due to the light scattering effect. The transparency values of the films loaded with $\mathrm{N}_{1}, \mathrm{~N}_{2}, \mathrm{~N}_{3}$, and $\mathrm{N}_{4}$ were quite close to those opacity values previously reported by Rivero et al. (2009) for composite and bi-layer films based on gelatin and chitosan $(0.68-0.99)$, while the $\mathrm{N}_{0}$ films showed a transparency value lower than that reported by Jridi et al. (2014) for gelatin-chitosan based films $(0.99 \pm 0.12)$.

\subsubsection{X-ray diffraction}

The presence of a strong interaction between the biopolymer matrix and NAC was confirmed by X-ray diffraction (XRD) analysis. All films exhibited an X-ray diffraction pattern characteristic of a partially crystalline material (Figure 3), with two defined diffraction peaks, the first in the region of $2 \theta$ $=10^{\circ}$, corresponding either to the crystalline triple helix structure of gelatin or the relatively regular crystal lattice of chitosan, and a second broader band at $2 \theta=20^{\circ}$, characteristic of an amorphous phase (Pereda et al., 2011; Valencia, Lourenço, Bittante, \& Sobral, 2016). Peaks observed in the films at approximately $32^{\circ}$ could be assigned to the (020) diffraction plane of hydrated chitosan crystals and relate to the films' preparation procedure (i.e. dissolution of chitosan in an acetic acid solution) or the chemical structure of the active compound incorporated (Pereda et al., 2011).

The incorporated active compounds through nanoemulsions $\mathrm{N}_{2}, \mathrm{~N}_{3}$ and $\mathrm{N}_{4}$, slightly changed the highest peak intensity, but in general, the profile of diffraction spectra of these films was similar to those obtained for the control films $\left(\mathrm{N}_{0}\right.$ and $\left.\mathrm{N}_{1}\right)$. The increase in the intensity of the peaks at $10^{\circ}$ for the $\mathrm{N}_{3}$ and $\mathrm{N}_{4}$ films, indicates that incorporation of nanoencapsulated GO into the biopolymer-blend matrix induces an increase in the films' crystallinity. A similar effect was observed by Rubilar et al. (2013) when incorporating carvacrol into chitosan based films. In contrast, Valenzuela, Abugoch, \& Tapia (2013) reported that the introduction of sunflower oil into a quinoa protein-chitosan based film generated a structure less crystalline, whilst Alexandre et al. (2016) reported no effect on the

Insert Figure 3 
In general, all films exhibited similar differential scanning calorimetry (DSC) curves (Figure 4). Curves from the first scan revealed a trace typical for partially crystalline material, with a glass transition, attributed to a fraction rich in gelatin, followed by a marked endothermal peak, associated to a helix-coil transition (Sobral et al., 2001; Valencia et al., 2016). In the second scan, a typical trace for amorphous material was observed, where a glass transition also occurred (Alexandre et al., 2016).

553

554

555

556

557

558

559

560

561

562

563

564

565

566

567

568

569

570

571

572

573

574

575

576

577

578

579

580

\section{Insert Figure 4}

The glass transition temperatures $\left(\mathrm{T}_{\mathrm{g}}\right)$ of all films did not appear to be affected by formulation characteristics ( $p>0.05$ ), remaining at approximately $46^{\circ} \mathrm{C}$ and $10^{\circ} \mathrm{C}$, in the first and second scan, respectively (Table 4). $T_{g}$ values were in agreement to those reported by Gómez-Estaca et al. (2009) for films based on gelatin incorporated with extracts $\left(\mathrm{T}_{\mathrm{g}}=42-47^{\circ} \mathrm{C}\right)$ and by Hosseini et al. (2013) for a blend of gelatin-chitosan with no incorporated species $\left(\mathrm{T}_{\mathrm{g}}=45-56^{\circ} \mathrm{C}\right)$.

All films showed a crystal melting temperature $\left(\mathrm{T}_{\mathrm{m}}\right)$ at approximately $55^{\circ} \mathrm{C}(\mathrm{p}>0.05)$. Nevertheless, only films loaded with the nanoemulsions exhibited an additional marked endothermal peak at $-18^{\circ} \mathrm{C}$ in both scans (Figure 5), which can be either attributed to the $\mathrm{T}_{\mathrm{m}}$ of the canola oil (-10 ${ }^{\circ} \mathrm{C}$ ) used for encapsulating the active compounds in nanodroplets, or even to the $\mathrm{T}_{\mathrm{m}}$ of the NAC themselves. Ma et al. (2012) also reported an extra endothermal peak at $-8^{\circ} \mathrm{C}$, attributed to the melting of olive oil that was emulsified into gelatin based films.

With regard to melting enthalpy $\left(\Delta \mathrm{H}_{\mathrm{g}}\right)$, this was significantly $(\mathrm{p}<0.05)$ reduced from $12.1 \mathrm{~J} / \mathrm{g}$ ( $\mathrm{N}_{0}$ films) to approximately $9.0 \mathrm{~J} / \mathrm{g}$ when the films were loaded with $\mathrm{N}_{1}, \mathrm{~N}_{2}, \mathrm{~N}_{3}$, or $\mathrm{N}_{4}$ (Table 4). The higher enthalpy value for the $\mathrm{N}_{0}$ films indicated that they had a higher level of renaturation compared to the nanoemulsion-loaded films, leading to an improved strength value (Jridi et al., 2014), as demonstrated by the TS data (Table 2). It is possible that the inter-chain distances of the gelatin macromolecules increased with nanoemulsions-loaded films and this is expected to decrease the entanglement of the gelatin chains and to increase their molecular mobility, reducing the melting enthalpy. Alexandre et al. (2016) also observed a reduction in the $\Delta \mathrm{H}_{\mathrm{g}}$ for films gelatin based films when ginger oil loaded-nanoemulsions were incorporated into the film matrix. However, Jridi et al. (2014) reported higher $T_{g}\left(64.7^{\circ} \mathrm{C}\right)$ and $\Delta \mathrm{H}_{\mathrm{g}}(66.4 \mathrm{~J} / \mathrm{g})$ values and no $\mathrm{T}_{\mathrm{m}}$ for fish skin gelatin-chitosan based films, maybe due to a better level of blending after intermolecular interaction between the gelatin and chitosan (Jridi et al., 2014). .

\subsubsection{Atomic force microscopy}


Atomic force microscopy (AFM) analyses were performed to observe the effect of

582

583

584

585

586

587

588

589

590

591

592

593

594

595

596

597

598

599

600

601

602

603

604

605

606

607

608

609

610

611

612

613

614

615

616

617 nanoemulsions incorporation on the surface topography of the films. Typical 3-D and 2-D surface topographic AFM images are presented in Figure 5. The incorporation of the nanoemulsions into the biopolymeric matrix led to a marked increase in both the average $\left(R_{\mathrm{a}}\right)$ and root-mean-square $\left(\mathrm{R}_{\mathrm{q}}\right)$ roughness of the films (Table 4). The $\mathrm{R}_{\mathrm{q}}$ increased drastically from $11.1 \mathrm{~nm}\left(\mathrm{~N}_{0}\right.$ films) to a maximum value of $58.6 \mathrm{~nm}$ ( $\mathrm{N}_{1}$ films) following the loading $\mathrm{N}_{1}, \mathrm{~N}_{2}, \mathrm{~N}_{3}$, or $\mathrm{N}_{4}$ into the films. The $\mathrm{R}_{\mathrm{a}}$ values showed a similar trend, increasing from $7.45 \mathrm{~nm}$ to $44.14 \mathrm{~nm}$. Atarés, Bonilla, \& Chiralt (2010), Hosseini et al. (2016), and Ma et al. (2012) have also reported an increase in terms of film roughness as a result of the incorporation of ginger oil, oregano oil, or olive oil into sodium caseinate, gelatin-chitosan blend, or gelatin based films, respectively. It has been proposed that this trend is potentially due to an enhancement in lipid aggregation and/or creaming phenomena, which are exacerbated by the drying step and ultimately result in an elevated level of irregularities on the films' surfaces (Ma et al., 2012).

\section{Insert Figure 5 \\ Insert Table 4}

\subsubsection{Environmental scanning electron microscopy (ESEM)}

The environmental scanning electron microscopy (ESEM) micrographs of the surface and cross-sectional morphology of the films revealed a continuous and homogeneous microstructure, without the presence of scratches, phase separation, and/or porosity due to the presence of trapped air cells (Figure 6). Furthermore, no evidence of oil droplets separation from the biopolymer-blend matrix was observed in the films loaded with nanoemulsions. However, the previously determined roughness difference between the $\mathrm{N}_{0}$ film and the ones loaded with $\mathrm{N}_{1}, \mathrm{~N}_{2}, \mathrm{~N}_{3}$, or $\mathrm{N}_{4}$ (Table 4) was also confirmed by the ESEM analysis (Figure 6). The marked roughness that was visible in the cross-sectional images of the films loaded with nanoemulsions has been previously reported by Hoque, Benjakul, \& Prodpran (2011), Hosseini et al. (2016), and Pérez-Córdoba \& Sobral (2017) for gelatin films or blends when these were loaded with some extract or essential oils (i.e. cinnamon, clove or star anise extracts and oregano or garlic oil).

Amongst the samples loaded with nanoemulsions, the $\mathrm{N}_{1}$ films appeared to possess the highest degree of surface and cross-sectional roughness, in agreement with the roughness data from AFM analyses (Figure 5). Then, this also suggests that NAC enhance the film roughness when incorporated into the matrix. Similarly, Acevedo-Fani et al. (2015), Chen et al. (2016), and Pérez-Córdoba \& Sobral (2017) have reported an improvement in the microstructures of films based on biopolymer blends when mixed with nanoemulsified essential oils.

\section{Insert Figure 6}




\subsubsection{Antimicrobial Activity}

The inhibitory activity against both $P$. aeruginosa (Gram negative) and L. monocytogenes (Gram positive) was determined measuring the clear zone surrounding the disks (inhibition zone). Halo formation $\left(65-138 \mathrm{~mm}^{2}\right)$ around the active films was observed only in the case of P. aeruginosa, which exhibited greater sensitivity compared to L. monocytogenes (Table 5). Similar observations were reported by Hafsa et al. (2016) and Kavoosi et al. (2014) when tested chitosan and gelatin based films with incorporated Eucalyptus globulus or Zataria multiflora essential oils. Paparella et al. (2008) suggested that the antimicrobial activity of some essential oils, is due to their interaction with enzymes located on the cell wall or the breakdown of the phospholipids present in the cell membrane, which results to increased permeability and leakage of cytoplasm.

The antimicrobial effect against $P$. aeruginosa could have been enhanced by the presence of chitosan in the blend, which has been widely reported as an antimicrobial compound (Elsabee \& Abdou, 2013; Pranoto et al., 2005; Yuan, Chen, \& Li, 2016). This has been ascribed to the presence of positively charged amino groups in the chitosan structure, which interact with the negatively charged microbial cell membranes and lead to the leakage of proteinaceous (and other intracellular) constituents from the microorganisms (Pereda et al., 2011, Pranoto et al., 2005). However, in this study all the G-Ch based films without active compounds ( $\mathrm{N}_{0}$ and $\mathrm{N}_{1}$ ) showed no activity against the tested bacteria (Table 5).

When active films were tested against L. monocytogenes, inhibition zones were not obvious ( $>0.05$ ); however, a clear zone was observed underneath the films. This observation could be associated to the limited diffusion of NAC from the films to the media (Pereda et al., 2011; Ponce, Roura, del Valle, \& Moreira, 2008) since in our case the active compounds were doubly encapsulated, into the nanodroplets and in the film matrix. Otoni et al. (2014), Seydim \& Sarikus (2006) and Sung et al. (2014) have reported activity against $L$. monocytogenes when using nanoemulsified cinnamaldehyde or GO into pectin/papaya puree, whey protein and low-density-polyethylene/ethylene-vinyl-acetate based films. In our study, nanoemulsified active compounds when not tested in films, showed high activity against L. monocytogenes (data not shown), which could be considered a derivative of the antimicrobial compounds and their delivery through nano-sized droplets, as reported by Kadri et al. (2017).

Converse to expectation, the combined application of nanoencapsulated Cin and GO within the film did not enhance the antimicrobial properties of the G-Ch based film $(p<0.05)$, although both of them had the ability to induce an inhibitory effect as bulk agent on the microorganism tested, principally due to their chemical components, such as cinnamic aldehyde and diallyl trisulfide, diallyl disulphide, methyl allyl trisulfide, and diallyl tetrasulfide, which are able to disrupt and penetrate the lipid structure of the bacteria cell membrane, leading to its destruction (Peng \& Li, 2014).

\subsubsection{Antioxidant properties}


The antioxidant activity of the films expressed as trolox equivalent ( $\mu \mathrm{mol} \mathrm{TE} / \mathrm{g}$ dried film) for the $\mathrm{DPPH}^{\bullet}$ and $\mathrm{ABTS}^{\bullet+}$ radicals, and the FRAP reagent is shown in Table 5. As expected, the control 1 film did not show any radical scavenging activity, in either of the $\mathrm{DPPH}^{\bullet}$ or $\mathrm{ABTS}^{\bullet+}$ tested method, and possessed very low FRAP scavenging activity.

Films loaded with NAC were capable of acting as stronger donors of hydrogen atoms or electrons until reduction of the stable purple-coloured radical $\mathrm{DPPH}^{\bullet}$ or blue-coloured radical $\mathrm{ABTS}^{\bullet+}$ converted to yellow-coloured DPPH-H or ABTS, respectively (Brand-Williams et al., 1995; Re et al., 1999). The film loaded with the nanoemulsion encapsulating $\alpha-t / C i n\left(N_{2}\right)$ exhibited the greatest antioxidant activity for both $\mathrm{DPPH}^{\bullet}$ and $\mathrm{ABTS}^{\bullet+}$ radicals, with values of $0.22 \pm 0.02$ and $2.63 \pm 0.12$ $\mu \mathrm{mol} \mathrm{TE} / \mathrm{g}$ film, respectively. This activity corresponded to the highest radical scavenging effect of that nanoemulsion $\left(\mathrm{N}_{2}\right)$ before incorporating in the film (data not shown). The results for $\mathrm{ABTS}^{\bullet+}$ radical scavenging of the films were comparable to those reported by Bonilla \& Sobral (2016) and PérezCórdoba \& Sobral (2017) for gelatin-chitosan based films loaded with boldo or guarana extracts, and nanoemulsified active compounds, respectively.

On the other hand, the incorporation of $\alpha$-t/GO-loaded nanoemulsion $\left(\mathrm{N}_{3}\right)$ into the film caused the highest $(\mathrm{p}<0.05)$ ferric reducing ability and, consequently, the best antioxidant activity measured by the FRAP assay with an increase of $91 \%$ and $51 \%$, respectively, when compared with either of the two control films $\left(\mathrm{N}_{0}\right.$ and $\left.\mathrm{N}_{1}\right)$. The FRAP assay gave the highest TE values, probably because of the direct contact of the film samples with the FRAP reagent during the reaction.

The antioxidant activity of the films is potentially attributed to the phenolic acids and terpenoids coming from the cinnamaldehyde, garlic oil, and principally, $\alpha$-tocopherol, which are able to quench free radicals by forming resonance-stabilized phenoxyl radicals (Dudonné, Vitrac, Coutière, Woillez, \& Mérillon, 2009). In addition to this, the contribution from the residual free amino groups of the chitosan molecule, which also react with free radicals forming stable macromolecular radicals and ammonium groups, should also be taken into account in terms of antioxidant activity (Yen, Yan, \& Mau, 2008; Yuan et al., 2016).

\section{Insert Table 5}

\section{Conclusions}

$\mathrm{O} / \mathrm{W}$ emulsions, with $\alpha$-toc, $\mathrm{Cin}$ and $\mathrm{GO}$ active compounds loaded within their dispersed phase droplets at high encapsulation efficiencies, were successfully formed at the nanoscale via a microfluidization technique. The formed nanoemulsions possessed a monomodal distribution and exhibited good physical stability over a 90 days storage and incorporation of the active species was not detrimental to either of these features. These nanoemulsions were subsequently incorporated into gelatin-chitosan (G-Ch) based films, which were shown to possess a homogeneous structure with a 
good distribution of nanoencapsulated active compounds (NAC) throughout the biopolymer matrix and without any unfavorable effects $(\mathrm{p}>0.05)$ on the films' original thickness, moisture content, glass transition, and melting temperature.

Nanoemulsion loading was found to enhance the films' resistance to water, reducing $(\mathrm{p}<0.05)$ their solubility, and increasing film elongation at break and light barrier properties, while also directly affecting their transparency, reducing their tensile strength and stiffness, and increasing their surface roughness. Therefore, nanoemulsions encapsulating active compounds are suitable to produce G-Ch based films, enhancing their physical and mechanical properties, antibacterial performance against $L$. monocytogenes and $P$. aeruginosa, and their radicals scavenging effect.

Films loaded with NAC have a potential applications in food packaging for food shelf-life improvement.Further studies on controlled release and foodstuff application are needed to know the real advantage of those active films when used on food.

Acknowledgements: To São Paulo Research Foundation (FAPESP) for first author's PhD fellowships Stablein for English revision, a Master student at the University of Illinois.

\section{Conflict of interest}

Authors declare that this work has not been published previously and there are no conflicts of interest.

\section{References}

Abdollahi, M., Rezaei, M., \& Farzi, G. (2012). A novel active bionanocomposite film incorporating rosemary essential oil and nanoclay into chitosan. Journal of Food Engineering, 111(2), 343 - 350. https://doi.org/10.1016/j.jfoodeng.2012.02.012

Acevedo-Fani, A., Salvia-Trujillo, L., Rojas-Graü, M. A., \& Martín-Belloso, O. (2015). Edible films from essential-oilloaded nanoemulsions: Physicochemical characterization and antimicrobial properties. Food Hydrocolloids, 47, 168177. https://doi.org/10.1016/j.foodhyd.2015.01.032

Ahmad, M., Benjakul, S., Prodpran, T., \& Agustini, T. W. (2012). Physico-mechanical and antimicrobial properties of gelatin film from the skin of unicorn leatherjacket incorporated with essential oils. Food Hydrocolloids, 28(1), 189199. https://doi.org/10.1016/j.foodhyd.2011.12.003

Alexandre, E. M. C., Lourenço, R. V., Quinta Barbosa Bittante, A. M., Moraes, I. C. F., \& Sobral, P. J. do A. (2016). Gelatin-based films reinforced with montmorillonite and activated with nanoemulsion of ginger essential oil for food packaging applications. Food Packaging and Shelf Life, 10, 87-96.

American Society for Testing and Materials D882/12 (2001). Standard Test Method for tensile properties of thin plastic sheeting. In Annual book of ASTM standards. http://dx.doi.org/10.1520/D0882-12

Anarjan, N., Mirhosseini, H., Baharin, B. S., \& Tan, C. P. (2011). Effect of processing conditions on physicochemical properties of sodium caseinate-stabilized astaxanthin nanodispersions. LWT - Food Science and Technology, 44(7), 1658-1665. https://doi.org/10.1016/j.lwt.2011.01.013

Arancibia, M., Giménez, B., López-Caballero, M. E., Gómez-Guillén, M. C., \& Montero, P. (2014). Release of cinnamon essential oil from polysaccharide bilayer films and its use for microbial growth inhibition in chilled shrimps. LWT Food Science and Technology, 59, 989-995. https://doi.org/10.1016/j.lwt.2014.06.031

Atarés, L., Bonilla, J., \& Chiralt, A. (2010). Characterization of sodium caseinate-based edible films incorporated with cinnamon or ginger essential oils. Journal of Food Engineering, 100(4), 678 - 687. https://doi.org/10.1016/j.jfoodeng.2010.05.018

Baron, R. D., Pérez, L. L., Salcedo, J. M., Córdoba, L. P., \& Sobral, P. J. do A. (2017). Production and characterization of films based on blends of chitosan from blue crab (Callinectes sapidus) waste and pectin from Orange (Citrus sinensis Osbeck) peel. International Journal of Biological Macromolecules, 98, 676-683. https://doi.org/10.1016/j.ijbiomac.2017.02.004 
Benbettaïeb, N., Kurek, M., Bornaz, S., \& Debeaufort, F. (2014). Barrier, structural and mechanical properties of bovine gelatin-chitosan blend films related to biopolymer interactions. Journal of the Science of Food and Agriculture, 94(12), 2409-2419. https://doi.org/10.1002/jsfa.6570

Bonilla, J., \& Sobral, P. J. A. (2016). Investigation of the physicochemical, antimicrobial and antioxidant properties of gelatin-chitosan edible film mixed with plant ethanolic extracts. Food Bioscience, 16, 17-25. https://doi.org/10.1016/j.fbio.2016.07.003

Brand-Williams, W., Cuvelier, M. E., \& Berset, C. (1995). Use of a free radical method to evaluate antioxidant activity. LWT - Food Science and Technology, 28(1), 25-30. https://doi.org/10.1016/S0023-6438(95)80008-5

Chen, H., Hu, X., Chen, E., Wu, S., Mcclements, D. J., Liu, S., \& Li, Y. (2016). Preparation, characterization, and properties of chitosan films with cinnamaldehyde nanoemulsions. Food Hydrocolloids, 61, 662-671. https://doi.org/10.1016/j.foodhyd.2016.06.034

Cheong, A. M., Tan, C. P., \& Nyam, K. L. (2017). Oil-in-water nanoemulsions under different storage temperatures. Industrial Crops and Products, 95, 374-382.

Cheong, J. N., Tan, C. P., Man, Y. B. C., \& Misran, M. (2008). $\alpha$-Tocopherol nanodispersions: Preparation, characterization and stability evaluation. Journal of Food Engineering, 89(2), 204-209. https://doi.org/10.1016/j.jfoodeng.2008.04.018

Dammak, I., Carvalho, R. A. de C., Trindade, C. S. F., Lourenço, R., \& Sobral, P. J. A. (2017). Properties of active gelatin films loaded with rutin-loaded nanoemulsions. International Journal of Biological Macromolecules, 98, 39-49. https://doi.org/http://dx.doi.org/10.1016/j.ijbiomac.2017.01.094

Dammak, I., \& Sobral, P. J. A. (2017). Formulation and Stability Characterization of Rutin-Loaded Oil-in-Water Emulsions. Food and Bioprocess Technology, 10(5), 926-939. https://doi.org/10.1007/s11947-017-1876-5

Davidov-Pardo, G., \& McClements, D. J. (2015). Nutraceutical delivery systems : Resveratrol encapsulation in grape seed oil nanoemulsions formed by spontaneous emulsification. Food Chemistry, 167, 205-212. https://doi.org/10.1016/j.foodchem.2014.06.082

Dias, D. D. O., Colombo, M., Kelmann, R. G., Kaiser, S., Lucca, L. G., Teixeira, H. F., \& Koester, L. S. (2014). Optimization of Copaiba oil-based nanoemulsions obtained by different preparation methods. Industrial Crops \& Products, 59, 154-162. https://doi.org/10.1016/j.indcrop.2014.05.007

Donsì, F., Annunziata, M., Sessa, M., \& Ferrari, G. (2011). Nanoencapsulation of essential oils to enhance their antimicrobial activity in foods. LWT - Food Science and Technology, 44(9), 1908-1914. https://doi.org/10.1016/j.lwt.2011.03.003

Donsì, F., Annunziata, M., Vincensi, M., \& Ferrari, G. (2012). Design of nanoemulsion-based delivery systems of natural antimicrobials : Effect of the emulsifier. Journal of Biotechnology, 159(4), 342-350. https://doi.org/10.1016/j.jbiotec.2011.07.001

Dudonné, S., Vitrac, X., Coutière, P., Woillez, M., \& Mérillon, J.-M. (2009). Comparative Study of Antioxidant Properties and Total Phenolic Content of 30 Plant Extracts of Industrial Interest Using DPPH, ABTS, FRAP, SOD, and ORAC Assays. Journal of Agricultural and Food Chemistry, 57(5), 1768-1774. https://doi.org/10.1021/jf803011r

Elsabee, M. Z., \& Abdou, E. S. (2013). Chitosan based edible films and coatings: a review. Materials Science \& Engineering. C, Materials for Biological Applications, 33(4), 1819-41. https://doi.org/10.1016/j.msec.2013.01.010

Fathi, M., Mozafari, M. R., \& Mohebbi, M. (2012). Nanoencapsulation of food ingredients using lipid based delivery systems. Trends in Food Science and Technology, 23(1), 13-27. https://doi.org/10.1016/j.tifs.2011.08.003

Ferreira, A. S., Nunes, C., Castro, A., Ferreira, P., \& Coimbra, M. A. (2014). Influence of grape pomace extract incorporation on chitosan films properties. Carbohydrate Polymers, 113, 490-499. https://doi.org/10.1016/j.carbpol.2014.07.032

Floury, J., Desrumaux, A., Axelos, M. a V, \& Legrand, J. (2003). Effect of high pressure homogenisation on methylcellulose as food emulsifier. Journal of Food Engineering, 58(3), 227-238. https://doi.org/10.1016/S0260-8774(02)00372-2

Gennadios, A., McHugh, T. H., Weller, C. L., \& Krochta, J. M. (1994). Edible coatings and films based on proteins. In: Edible Coat. Films Improve Food Qual. (Krochta, J. M., Baldwin, E. A., and Nisperos-Carriedo, M. O., eds.), pp. 201-277. Technomic Publishing Company, Inc., Lancaster, PA.

Gómez-Estaca, J., Giménez, B., Montero, P., \& Gómez-Guillén, M. C. (2009). Incorporation of antioxidant borage extract into edible films based on sole skin gelatin or a commercial fish gelatin. Journal of Food Engineering, 92(1), 78-85. https://doi.org/10.1016/j.jfoodeng.2008.10.024

Gómez-Estaca, J., López de Lacey, A., López-Caballero, M. E., Gómez-Guillén, M. C., \& Montero, P. (2010). Biodegradable gelatin-chitosan films incorporated with essential oils as antimicrobial agents for fish preservation. Food Microbiology, 27(7), 889-96. https://doi.org/10.1016/j.fm.2010.05.012

Gómez-Guillén, M. C., Pérez-Mateos, M., Gómez-Estaca, J., López-Caballero, E., Giménez, B., \& Montero, P. (2009). Fish gelatin: a renewable material for developing active biodegradable films. Trends in Food Science and Technology, 20(1), 3 - 16. https://doi.org/10.1016/j.tifs.2008.10.002

Gontard, N. ; Duchez, C.; Cuq, J.L. ; Guilbert, S. (1994). Edible composite films of wheat gluten and lipids: water vapour permeability and others physical properties. International Journal of Food Science and Technology, 29, 39-50. https://doi.org/10.1111/j.1365-2621.1994.tb02045.

Grill, J. M., Ogle, J, \& Miller, S. A. (2006). An Efficient and Practical System for the Catalytic Oxidation of Alcohols, Aldehydes, and $\alpha, \beta$-Unsaturated Carboxylic Acids. The Journal of Organic Chemistry, 71(25), 9291 - 9296. https://doi.org/10.1021/JO0612574

Hafsa, J., Smach, M. ali, Ben Khedher, M. R., Charfeddine, B., Limem, K., Majdoub, H., \& Rouatbi, S. (2016). Physical, antioxidant and antimicrobial properties of chitosan films containing Eucalyptus globulus essential oil. LWT - Food Science and Technology, 68, 356-364. https://doi.org/10.1016/j.lwt.2015.12.050

Heurtault, B., Saulnier, P., Pech, B., Proust, J. E., \& Benoit, J. P. (2003). Physico-chemical stability of colloidal lipid particles. Biomaterials, 24(23), 4283-4300. https://doi.org/10.1016/S0142-9612(03)00331-4 
Hoque, M. S., Benjakul, S., \& Prodpran, T. (2011). Properties of film from cuttlefish (Sepia pharaonis) skin gelatin incorporated with cinnamon, clove and star anise extracts. Food Hydrocolloids, 25(5), 1085-1097. https://doi.org/10.1016/j.foodhyd.2010.10.005

Hosseini, S., Rezaei, M., Zandi, M., \& Ghavi, F. F. (2013). Preparation and functional properties of fish gelatin-chitosan blend edible films. Food Chemistry, 136(3-4) 1490 - 1495. https://doi.org/10.1016/j.foodchem.2012.09.081

Hosseini, S. F., Rezaei, M., Zandi, M., \& Farahmandghavi, F. (2016). Development of bioactive fish gelatin/chitosan nanoparticles composite films with antimicrobial properties. Food Chemistry, 194, 1266-1274. https://doi.org/10.1016/j.foodchem.2015.09.004

Hsu, J. P., \& Nacu, A. (2003). Behavior of soybean oil-in-water emulsion stabilized by nonionic surfactant. Journal of Colloid and Interface Science, 259(2), 374-381. https://doi.org/10.1016/S0021-9797(02)00207-2

Jo, Y. J., \& Kwon, Y. J. (2014). Characterization of $\beta$-carotene nanoemulsions prepared by microfluidization technique. Food Science and Biotechnology, 23(1), 107-113. https://doi.org/10.1007/s10068-014-0014-7

Jridi, M., Hajji, S., Ayed, H. Ben, Lassoued, I., Mbarek, A., Kammoun, M., \& Nasri, M. (2014). Physical, structural, antioxidant and antimicrobial properties of gelatin-chitosan composite edible films. International Journal of Biological Macromolecules, 67, 373 - 379. https://doi.org/10.1016/j.ijbiomac.2014.03.054

Kadri, H. El, Devanthi, P. V. P., Overton, T. W., \& Gkatzionis, K. (2017). Do oil-in-water (O/W) nano-emulsions have an effect on survival and growth of bacteria? Food Research International, 101, 114-128. https://doi.org/10.1016/j.foodres.2017.08.064

Kanatt, S. R., Rao, M. S., Chawla, S. P., \& Sharma, A. (2012). Active chitosan-polyvinyl alcohol films with natural extracts. Food Hydrocolloids, 29 (2), 290-297. https://doi.org/10.1016/j.foodhyd.2012.03.005

Kavoosi, G., Mohammad, S., Dadfar, M., Purfard, A. M., \& Mehrabi, R. (2013). Antioxidant and antibacterial properties of gelatin films incorporated with carvacrol. Journal of Food Safety, 33(4), 423 - 432. https://doi.org/10.1111/jfs.12071

Kavoosi, G., Rahmatollahi, A., Mohammad Mahdi Dadfar, S., \& Mohammadi Purfard, A. (2014). Effects of essential oil on the water binding capacity, physico-mechanical properties, antioxidant and antibacterial activity of gelatin films. $L W T$ - Food Science and Technology, 57, 556-561. https://doi.org/10.1016/j.lwt.2014.02.008

Kurek, M., Galus, S., \& Debeaufort, F. (2014). Surface, mechanical and barrier properties of bio-based composite films based on chitosan and whey protein. Food Packaging and Shelf Life, 1, 56-67. https://doi.org/10.1016/j.fps1.2014.01.001

Limpisophon, K., Tanaka, M., \& Osako, K. (2010). Characterisation of gelatin-fatty acid emulsion films based on blue shark (Prionace glauca) skin gelatin. Food Chemistry, 122(4), 1095-1101. https://doi.org/10.1016/j.foodchem.2010.03.090

Ma, W., Tang, C.-H., Yin, S.-W., Yang, X.-Q., Wang, Q., Liu, F., \& Wei, Z.-H. (2012). Characterization of gelatin-based edible films incorporated with olive oil. Food Research International, 49(1), 572-579. https://doi.org/10.1016/j.foodres.2012.07.037

Mao, L., Yang, J., Xu, D., Yuan, F., \& Gao, Y. (2010). Effects of Homogenization Models and Emulsifiers on the Physicochemical Properties of $\beta$-Carotene Nanoemulsions. Journal of Dispersion Science and Technology, 31(7), 986-993. https://doi.org/10.1080/01932690903224482

Martins, J. T., Cerqueira, M. A., \& Vicente, A. A. (2012). Influence of $\alpha$-tocopherol on physicochemical properties of chitosan-based films. Food Hydrocolloids, 27(1), 220-227. https://doi.org/10.1016/j.foodhyd.2011.06.011

Mihaly Cozmuta, A., Turila, A., Apjok, R., Ciocian, A., Mihaly Cozmuta, L., Peter, A., \& Benković, T. (2015). Preparation and characterization of improved gelatin films incorporating hemp and sage oils. Food Hydrocolloids, 49, 144-155. https://doi.org/10.1016/j.foodhyd.2015.03.022

Nejadmansouri, M., Mohammad, S., Hosseini, H., Niakosari, M., Yousefi, G. H., \& Golmakani, M. T. (2016). Physicochemical properties and storage stability of ultrasound-mediated WPI-stabilized fish oil nanoemulsions. Food Hydrocolloids, 61, 801-811. https://doi.org/10.1016/j.foodhyd.2016.07.011

Noronha, C. M., De Carvalho, S. M., Lino, R. C., \& Barreto, P. L. M. (2014). Characterization of antioxidant methylcellulose film incorporated with $\alpha$-tocopherol nanocapsules. Food Chemistry, 159, 529-535. https://doi.org/10.1016/j.foodchem.2014.02.159

Nhan, P. P., \& Hoa, N. K. (2013). Effect of Light and Storage Time on Vitamin E in Pharmaceutical Products. British Journal of Pharmacology and Toxicology, 4(5), 176-180. http://maxwellsci.com/print/bjpt/v4-176-180.pdf

Otoni, C. G., Avena-Bustillos, R. J., Olsen, C. W., Bilbao-Sáinz, C., \& McHugh, T. H. (2016). Mechanical and water barrier properties of isolated soy protein composite edible films as affected by carvacrol and cinnamaldehyde micro and nanoemulsions. Food Hydrocolloids. 57, 72 - 79. https://doi.org/10.1016/j.foodhyd.2016.01.012

Otoni, C. G., De Moura, M. R., Aouada, F. A., Camilloto, G. P., Cruz, R. S., Lorevice, M. V, Mattoso, L. H. C. (2014). Antimicrobial and physical-mechanical properties of pectin/papaya puree/cinnamaldehyde nanoemulsion edible composite films. https://doi.org/10.1016/j.foodhyd.2014.04.013

Paparella, A., Taccogna, L., Aguzzi, I., Chaves-López, C., Serio, A., Marsilio, F., \& Suzzi, G. (2008). Flow cytometric assessment of the antimicrobial activity of essential oils against Listeria monocytogenes. Food Control, 19(12), 11741182. https://doi.org/10.1016/j.foodcont.2008.01.002

Peng, Y., \& Li, Y. (2014). Combined effects of two kinds of essential oils on physical, mechanical and structural properties of chitosan films. Food Hydrocolloids, 36, 287-293. https://doi.org/10.1016/j.foodhyd.2013.10.013

Pereda, M., Ponce, A. G., Marcovich, N. E., Ruseckaite, R. A., \& Martucci, J. F. (2011). Chitosan-gelatin composites and bi-layer films with potential antimicrobial activity. Food Hydrocolloids, 25(5), 1372-1381. https://doi.org/10.1016/j.foodhyd.2011.01.001

Pérez-Córdoba, L. J., \& Sobral, P. J. A. (2017). Physical and antioxidant properties of films based on gelatin, gelatinchitosan or gelatin-sodium caseinate blends loaded with nanoemulsified active compounds. Journal of Food Engineering, 213, 47-53. https://doi.org/10.1016/j.jfoodeng.2017.05.023

Péroval, C., Debeaufort, F., Despré, D., \& Voilley, A. (2002). Edible Arabinoxylan-Based Films. 1. Effects of Lipid Type on 
Water Vapor Permeability, Film Structure, and Other Physical Characteristics. Journal of Agriculture and Food Chemistry, 50(14), 3977 - 3983. https://doi.org/10.1021/JF0116449

Ponce, A. G., Roura, S. I., del Valle, C. E., \& Moreira, M. R. (2008). Antimicrobial and antioxidant activities of edible coatings enriched with natural plant extracts: In vitro and in vivo studies. Postharvest Biology and Technology, 49(2), 294 - 300. https://doi.org/10.1016/j.postharvbio.2008.02.013

Pranoto, Y., Rakshit, S. K., \& Salokhe, V. M. (2005). Enhancing antimicrobial activity of chitosan films by incorporating garlic oil, potassium sorbate and nisin. LWT - Food Science and Technology, 38(8), 859-865. https://doi.org/10.1016/j.lwt.2004.09.014

Re, R., Pellegrini, N., Proteggente, A., Pannala, A., Yang, M., \& Rice-Evans, C. (1999). Antioxidant Activity Applying an Improved Abts Radical Cation Decolorization Assay, Free radical biology and medicine, 26(9-10), 1231-1237.

Rhim, J. W., \& Ng, P. K. W. (2007). Natural biopolymer-based nanocomposite films for packaging applications. Critical Reviews in Food Science and Nutrition, 47(4), 411-433. https://doi.org/10.1080/10408390600846366

Rivero, S., García, M. A., \& Pinotti, A. (2009). Composite and bi-layer films based on gelatin and chitosan. Journal of Food Engineering, 90, 531-539. https://doi.org/10.1016/j.jfoodeng.2008.07.021

Rubilar, J. F., Cruz, R. M. S., Silva, H. D., Vicente, A. A., Khmelinskii, I., \& Vieira, M. C. (2013). Physico-mechanical properties of chitosan films with carvacrol and grape seed extract. Journal of Food Engineering, 115(4), 466-474. https://doi.org/10.1016/j.jfoodeng.2012.07.009

Saberi, A. H., Fang, Y., \& McClements, D. J. (2013). Fabrication of vitamin E-enriched nanoemulsions: Factors affecting particle size using spontaneous emulsification. Journal of Colloid and Interface Science, 391(1), 95-102. https://doi.org/10.1016/j.jcis.2012.08.069

Salvia-Trujillo, L., Rojas-Graü, M. A., Soliva-Fortuny, R., \& Martín-Belloso, O. (2013). Effect of processing parameters on physicochemical characteristics of microfluidized lemongrass essential oil-alginate nanoemulsions. Food Hydrocolloids, 30(1), 401-407. https://doi.org/10.1016/j.foodhyd.2012.07.004

Sari, T. P., Mann, B., Kumar, R., Singh, R. R. B., Sharma, R., Bhardwaj, M., \& Athira, S. (2014). Preparation and characterization of nanoemulsion encapsulating curcumin. Food Hydrocolloids, 43, 540 - 546. https://doi.org/10.1016/j.foodhyd.2014.07.011

Sasaki, R. S., Mattoso, L. H. C., \& de Moura, M. R. (2016). New Edible Bionanocomposite Prepared by Pectin and Clove Essential Oil Nanoemulsions. Journal of Nanoscience and Nanotechnology, 16(6), 6540-6544. https://doi.org/10.1166/jnn.2016.11702

Seydim, A. C., \& Sarikus, G. (2006). Antimicrobial activity of whey protein based edible films incorporated with oregano, rosemary and garlic essential oils. Food Research International, 39, 639-644. https://doi.org/10.1016/j.foodres.2006.01.013

Soazo, M., Rubiolo, A. C., \& Verdini, R. A. (2011). Effect of drying temperature and beeswax content on moisture isotherms of whey protein emulsion film. Procedia Food Science, 1, 210-215. https://doi.org/10.1016/J.profoo.2011.09.033

Sobral, P. J. A., Menegalli, F. C., Hubinger, M. D., \& Roques, M. A. (2001). Mechanical, water vapor barrier and thermal properties of gelatin based edible films. Food Hydrocolloids, 15(4-6), 423-432. https://doi.org/10.1016/S0268$005 \mathrm{X}(01) 00061-3$

Statgraphics Centurion XV Software (StatPoint, Inc.), 2006. Version 15.2. 05. Statistical Graphics Corp., Warrenton, Virginia.

Sung, S. Y., Sin, L. T., Tee, T. T., Bee, S. T., \& Rahmat, A. R. (2014). Effects of Allium sativum essence oil as antimicrobial agent for food packaging plastic film. Innovative Food Science and Emerging Technologies, 26, 406414. https://doi.org/10.1016/j.ifset.2014.05.009

Tan, C. P., \& Nakajima, M. (2005). $\beta$-Carotene nanodispersions: Preparation, characterization and stability evaluation. Food Chemistry, 92, 661-671. https://doi.org/10.1016/j.foodchem.2004.08.044

Tongnuanchan, P., Benjakul, S., \& Prodpran, T. (2012). Properties and antioxidant activity of fish skin gelatin film incorporated with citrus essential oils. Food Chemistry, 134(3), 1571-1579. https://doi.org/10.1016/j.foodchem.2012.03.094

Tongnuanchan, P., Benjakul, S., \& Prodpran, T. (2013). Physico-chemical properties, morphology and antioxidant activity of film from fish skin gelatin incorporated with root essential oils. Journal of Food Engineering, 117(3), 350-360. https://doi.org/10.1016/j.jfoodeng.2013.03.005

Tongnuanchan, P., Benjakul, S., \& Prodpran, T. (2014). Structural, morphological and thermal behaviour characterisations of fi sh gelatin fi $1 \mathrm{~m}$ incorporated with basil and citronella essential oils as affected by surfactants. Food Hydrocolloids, 41, 33-43. https://doi.org/10.1016/j.foodhyd.2014.03.015

Troncoso, E., Aguilera, J. M., \& McClements, D. J. (2012). Fabrication, characterization and lipase digestibility of foodgrade nanoemulsions. Food Hydrocolloids, 27(2), 355-363. https://doi.org/10.1016/j.foodhyd.2011.10.014

Valencia, G. A., Lourenço, R. V., Bittante, A. M. Q. B., \& Sobral, P. J. A. (2016). Physical and morphological properties of nanocomposite films based on gelatin and Laponite. Applied Clay Science, 124-125, 260-266. https://doi.org/10.1016/j.clay.2016.02.023

Valenzuela, C., Abugoch, L., \& Tapia, C. (2013). Quinoa protein-chitosan-sunflower oil edible film: Mechanical, barrier and structural properties. LWT - Food Science and Technology, 50(2), 531-537. https://doi.org/10.1016/j.lwt.2012.08.010

Wang, J., Cao, Y., Sun, B., \& Wang, C. (2011). Physicochemical and release characterisation of garlic oil- b -cyclodextrin inclusion complexes. Food Chemistry, 127(4), 1680-1685. https://doi.org/10.1016/j.foodchem.2011.02.036

Wayne, P. (2006). Performance Standarts for Antimicrobial Disk Susceptibility Tests; Approved Standard; 9 Edition. Clinical and laboratory standards institute (Vol. 26). http://demo.nextlab.ir/getattachment/27407437-3d73-4048-823981857d68cf3d/CLSI-M2-A9.aspx

Wei, Q.-Y., Xiong, J.-J., Jiang, H., Zhang, C., \& Wen Ye. (2011). The antimicrobial activities of the cinnamaldehyde 
adducts with amino acids. International Journal of Food Microbiology, 150(2-3), 164-70. https://doi.org/10.1016/j.ijfoodmicro.2011.07.034

Wu, J., Chen, S., Ge, S., Miao, J., Li, J., \& Zhang, Q. (2013). Preparation, properties and antioxidant activity of an active fi $\mathrm{lm}$ from silver carp ( Hypophthalmichthys molitrix ) skin gelatin incorporated with green tea extract. Food Hydrocolloids, 32, 42-51. https://doi.org/10.1016/j.foodhyd.2012.11.029

Yang, Y., \& McClements, D. J. (2013). Encapsulation of vitamin E in edible emulsions fabricated using a natural surfactant. Food Hydrocolloids, 30(2), 712-720. https://doi.org/10.1016/j.foodhyd.2012.09.003

Yen, M.-T., Yan, J.-H., \& Mau, J.-L. (2008). Antioxidant properties of chitosan from crab shells. Carbohydrate Polymers, 74(4), 840-844. https://doi.org/10.1016/J.CARBPOL.2008.05.003

Yuan, G., Chen, X., \& Li, D. (2016). Chitosan films and coatings containing essential oils: The antioxidant and antimicrobial activity, and application in food systems. Food Research International, 89, 117-128. https://doi.org/10.1016/j.foodres.2016.10.004 
958 Figure 1. Droplet size distributions of O/W nanoemulsions containing encapsulated active compounds as 959 a function of storage time (all systems stored at $4{ }^{\circ} \mathrm{C}$ ). (a) Control (no encapsulated species); (b) $\alpha$ 960 tocopherol/cinnamaldehyde; (c) $\alpha$-tocopherol/garlic oil; and (d) $\alpha$-tocopherol/ cinnamaldehyde and garlic 961 oil.

Figure 2. (a) 3-D AFM topographic images, and (b) profile of the height values along the sample in 964 the marked area of 2D AFM images of O/W nanoemulsions containing encapsulated active compounds. $* \alpha$-t: $\alpha$-tocopherol, Cin: cinnamaldehyde, GO: garlic oil.

Figure 4. DSC thermograms of gelatin-chitosan films loaded with $\mathrm{O} / \mathrm{W}$ nanoemulsions containing encapsulated active compounds. $\mathrm{N}_{0}$ - Control 1: film without nanoemulsion; $\mathrm{N}_{1}$ - Control 2: film with control nanoemulsion (no encapsulated species); $\mathrm{N}_{2}$ : $\alpha$-tocopherol/cinnamaldehyde; $\mathrm{N}_{3}$ : $\alpha$ tocopherol/garlic oil; $\mathrm{N}_{4}$ : $\alpha$-tocopherol/cinnamaldehyde and garlic oil-loaded nanoemulsion. Straight traces correspond to the first scan and broken traces for the second scan.

Figure 5. AFM micrographs of (a) 3D topography and (b) 2D surface of gelatin-chitosan films loaded with $\mathrm{O} / \mathrm{W}$ nanoemulsions containing encapsulated active compounds. $\mathrm{N}_{0}$ - Control 1: film without nanoemulsion; $\mathrm{N}_{1}$ - Control 2: film with control nanoemulsion (no encapsulated species); $\mathrm{N}_{2}: \alpha-$ tocopherol/cinnamaldehyde; $\mathrm{N}_{3}$ : $\alpha$-tocopherol/garlic oil; $\mathrm{N}_{4}$ : $\alpha$-tocopherol/cinnamaldehyde and garlic oil-loaded nanoemulsion.

Figure 6. ESEM micrographs of the a) surface and b) cross section of gelatin-chitosan films loaded nanoemulsion; $\mathrm{N}_{1}$ - Control 2: film with control nanoemulsion (no encapsulated species); $\mathrm{N}_{2}: \alpha-$ tocopherol/cinnamaldehyde; $\mathrm{N}_{3}$ : $\alpha$-tocopherol/garlic oil; $\mathrm{N}_{4}$ : $\alpha$-tocopherol/cinnamaldehyde and garlic 

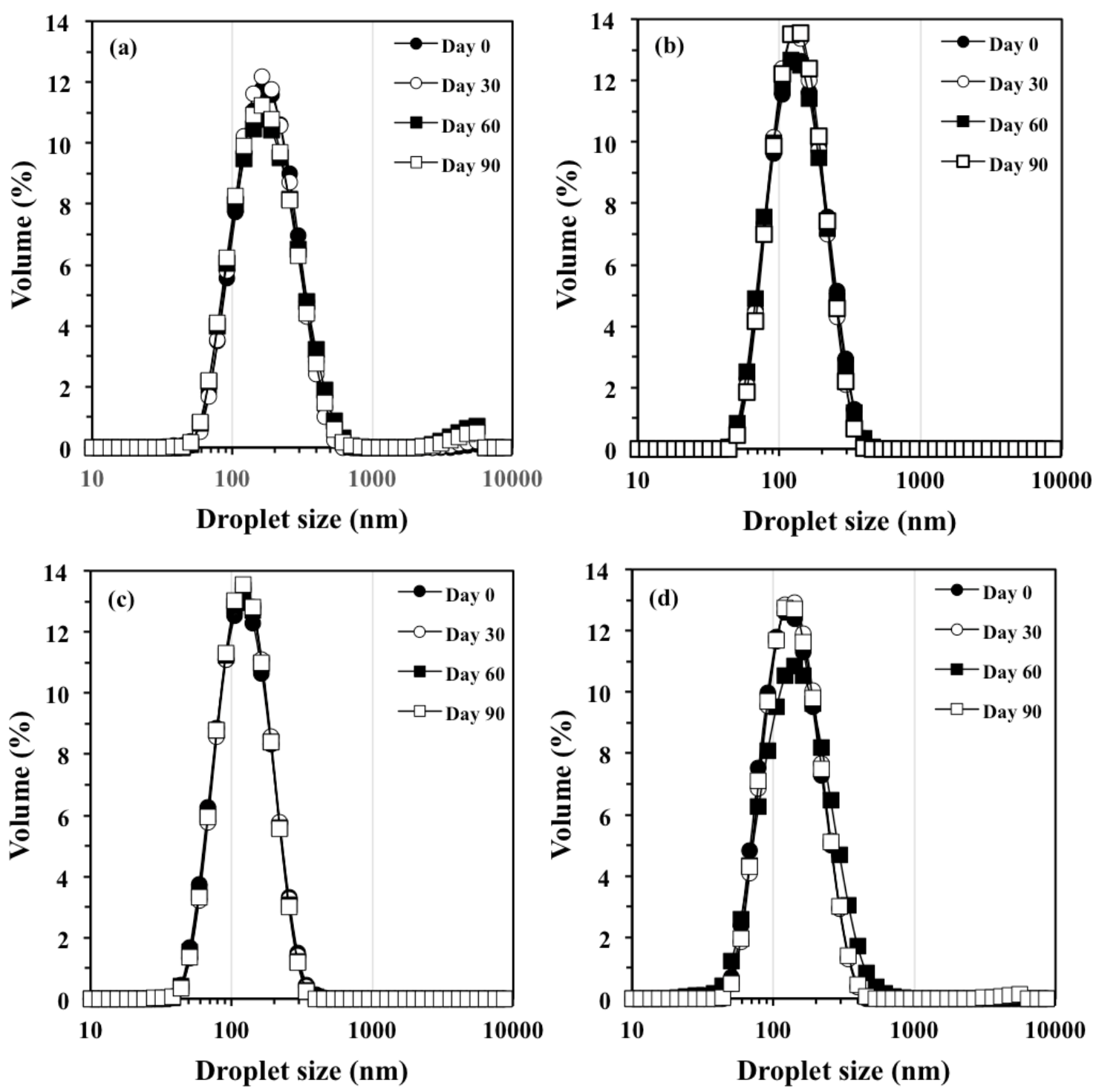

Figure 1. Droplet size distributions of $\mathrm{O} / \mathrm{W}$ nanoemulsions containing encapsulated active compounds as a function of storage time (all systems stored at $4{ }^{\circ} \mathrm{C}$ ). (a) Control (no encapsulated species); (b) $\alpha$-tocopherol/cinnamaldehyde; (c) $\alpha$-tocopherol/garlic oil; and (d) $\alpha$-tocopherol/ cinnamaldehyde and garlic oil. 
(a)
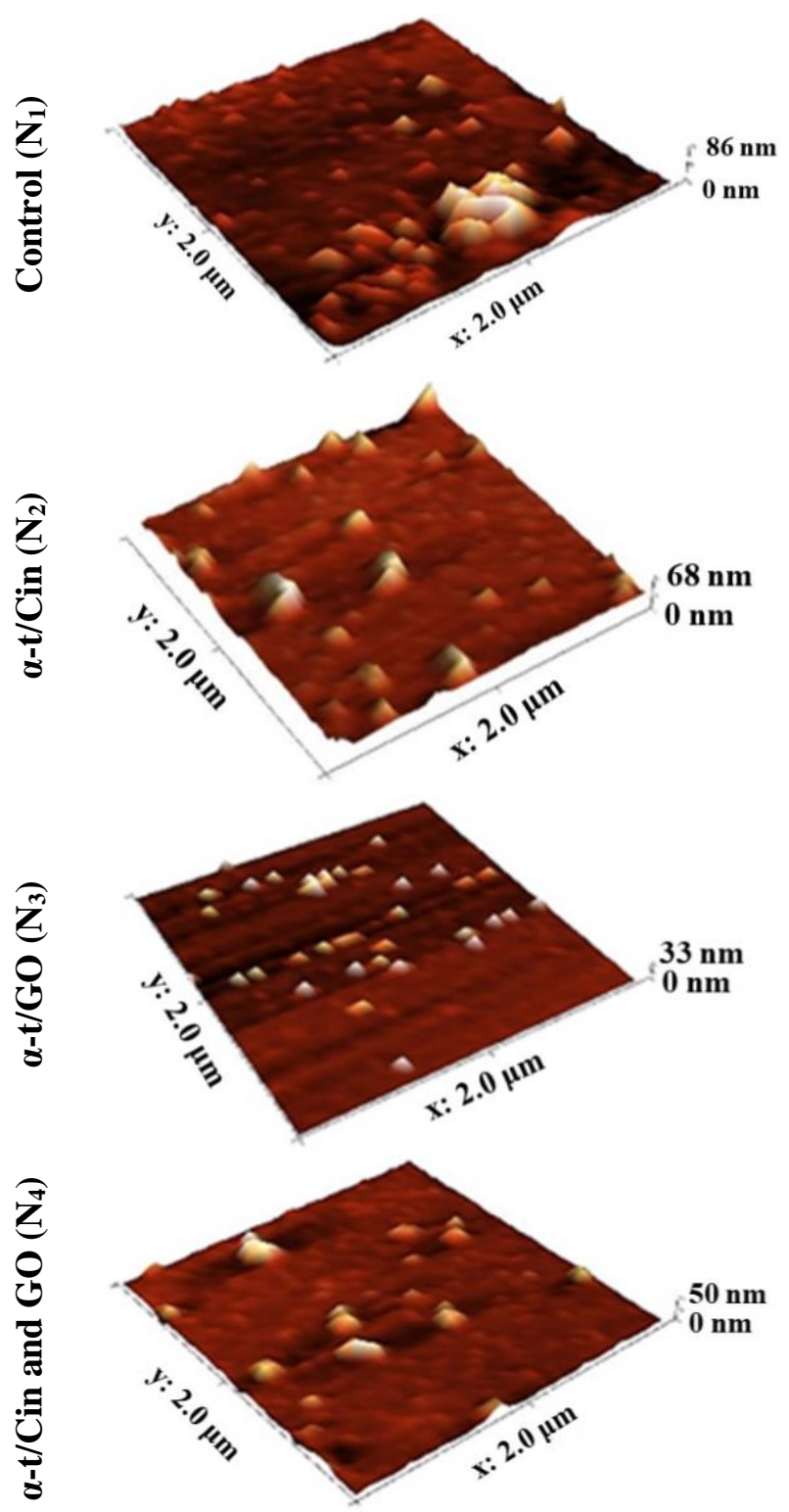

(b)
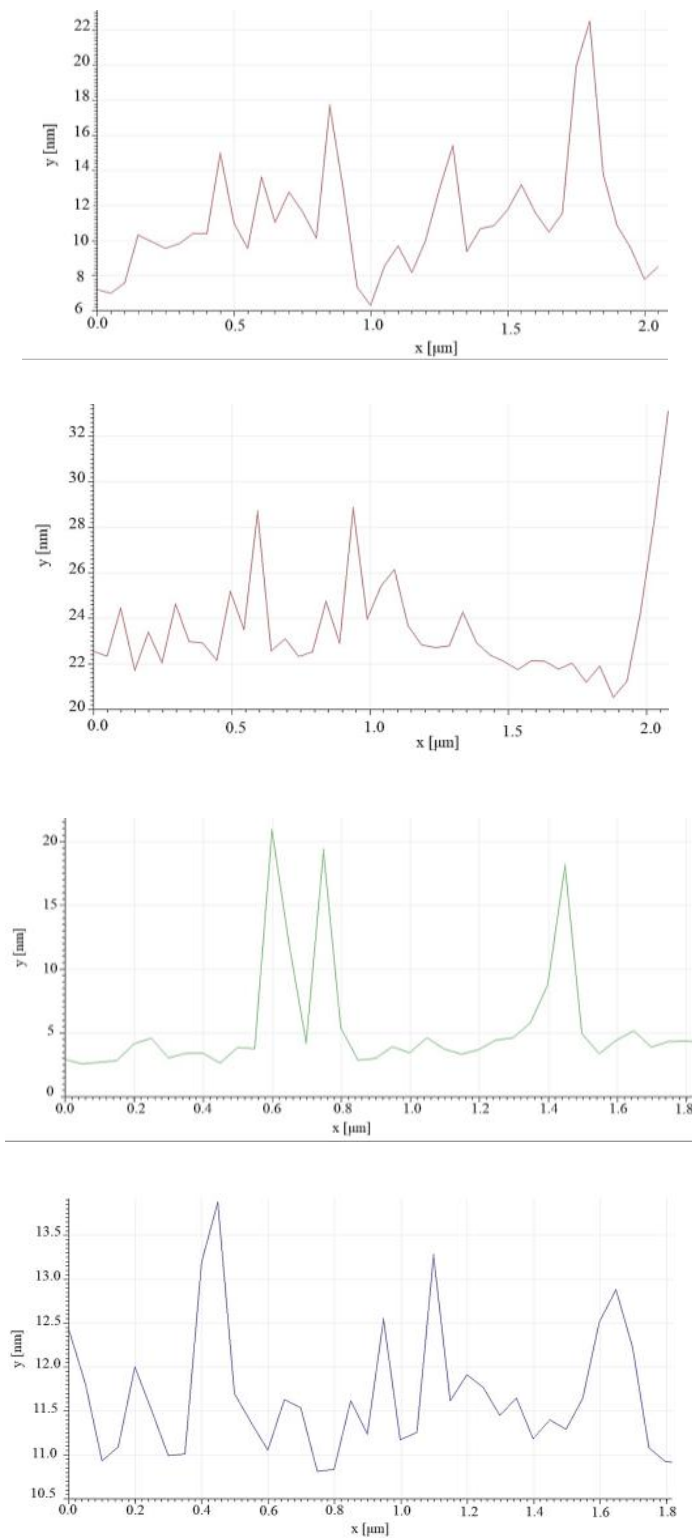

Figure 2. (a) 3-D AFM topographic images, and (b) profile of the height values along the sample in the marked area of 2D AFM images of O/W nanoemulsions containing encapsulated active compounds. ${ }^{*} \alpha$-t: $\alpha$-tocopherol, Cin: cinnamaldehyde, GO: garlic oil. 


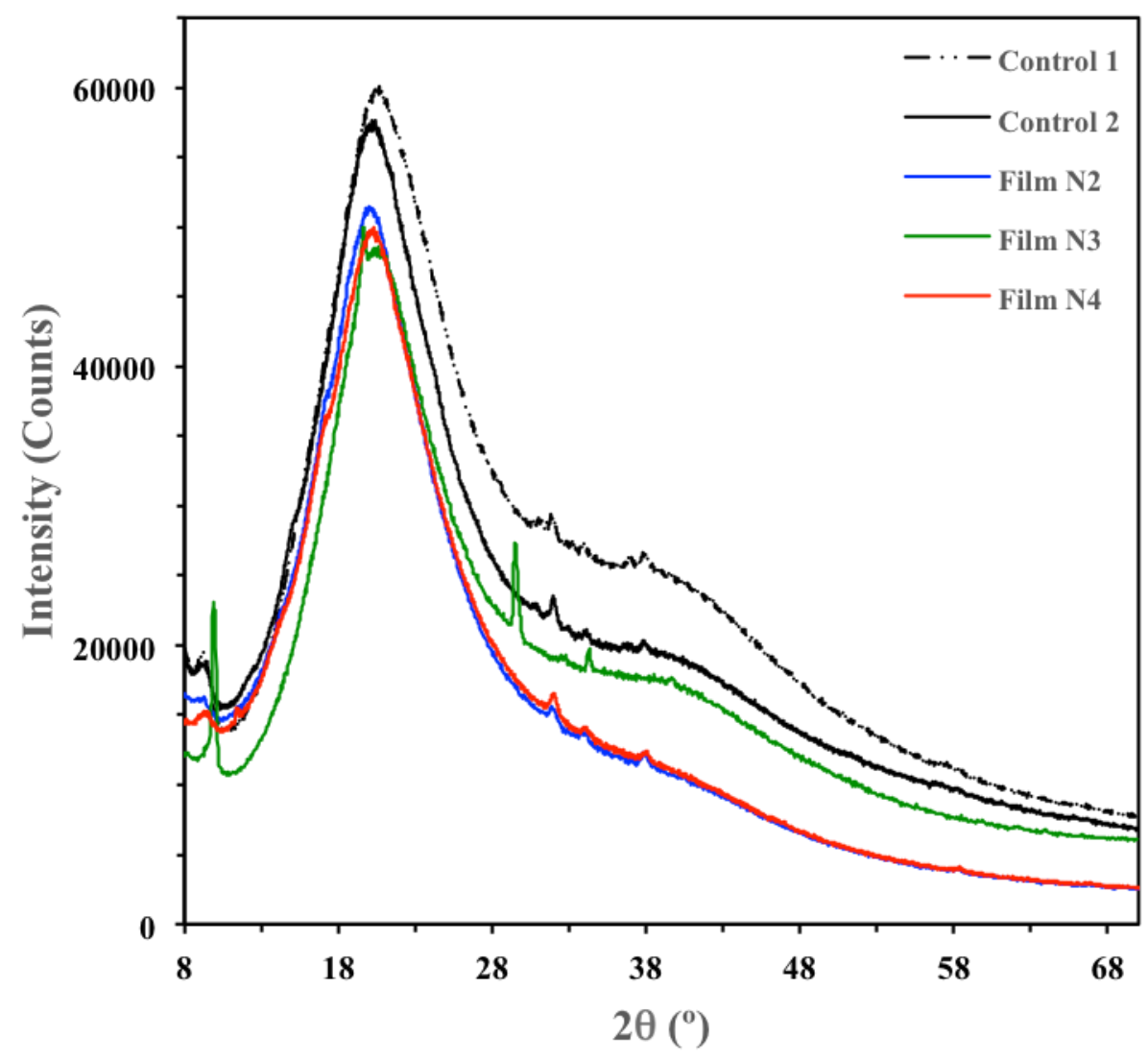

Figure 3. Diffractograms of gelatin-chitosan films loaded with $\mathrm{O} / \mathrm{W}$ nanoemulsions containing encapsulated active compounds. $\mathrm{N}_{0}$ - Control 1: film without nanoemulsion; $\mathrm{N}_{1}$ - Control 2: film with control nanoemulsion (no encapsulated species); $\mathrm{N}_{2}: \alpha$-tocopherol/cinnamaldehyde; $\mathrm{N}_{3}: \alpha$ tocopherol/garlic oil; $\mathrm{N}_{4}$ : $\alpha$-tocopherol/cinnamaldehyde and garlic oil-loaded nanoemulsion. 


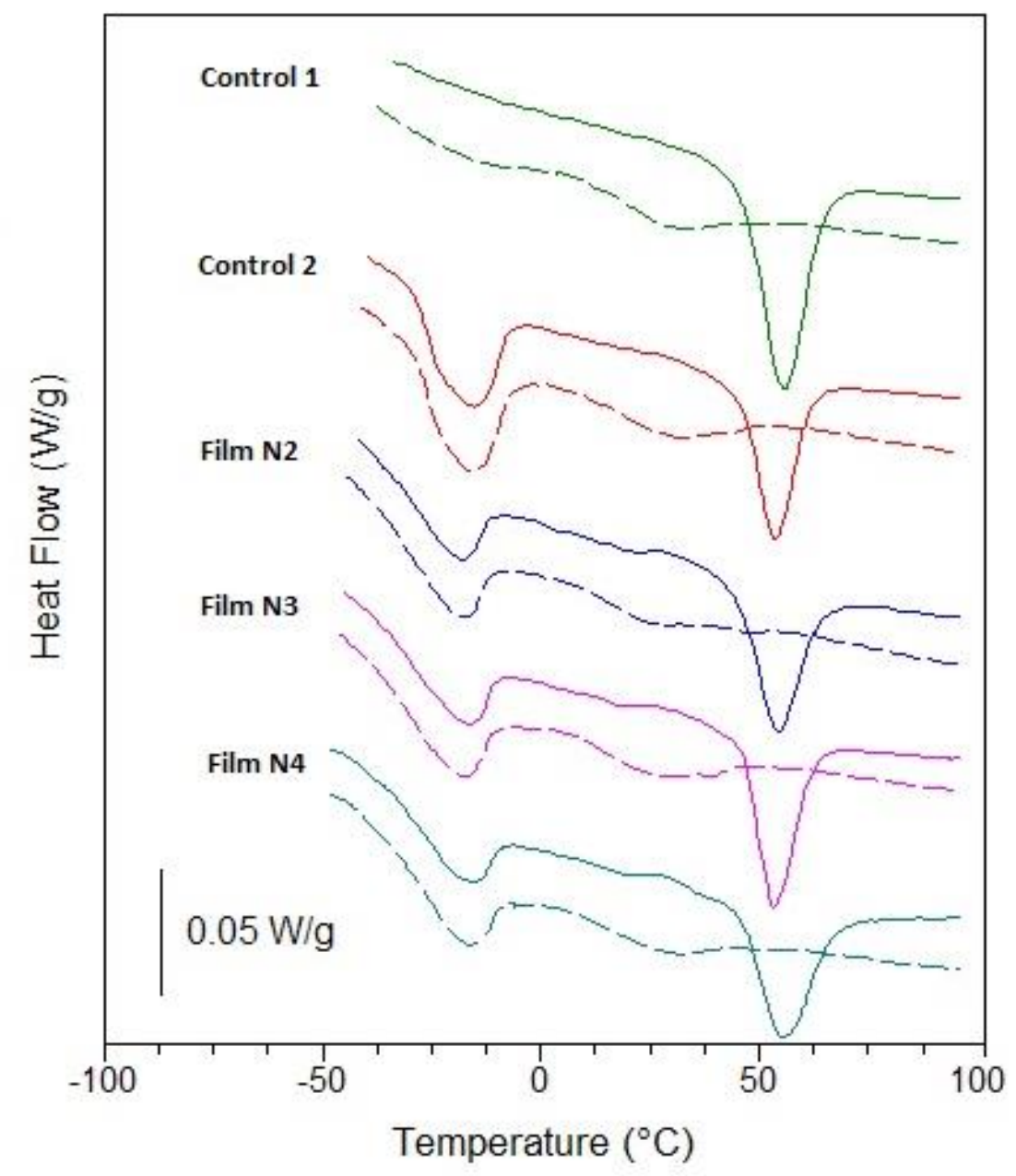

Figure 4. DSC thermograms of gelatin-chitosan films loaded with $\mathrm{O} / \mathrm{W}$ nanoemulsions containing encapsulated active compounds. $\mathrm{N}_{0}$ - Control 1: film without nanoemulsion; $\mathrm{N}_{1}$ Control 2: film with control nanoemulsion (no encapsulated species); $\mathrm{N}_{2}: \alpha-$ tocopherol/cinnamaldehyde; $\mathrm{N}_{3}$ : $\alpha$-tocopherol/garlic oil; $\mathrm{N}_{4}$ : $\alpha$-tocopherol/cinnamaldehyde and garlic oil-loaded nanoemulsion. Straight traces correspond to the first scan and broken traces for the second scan. 
(a): 3D Topography
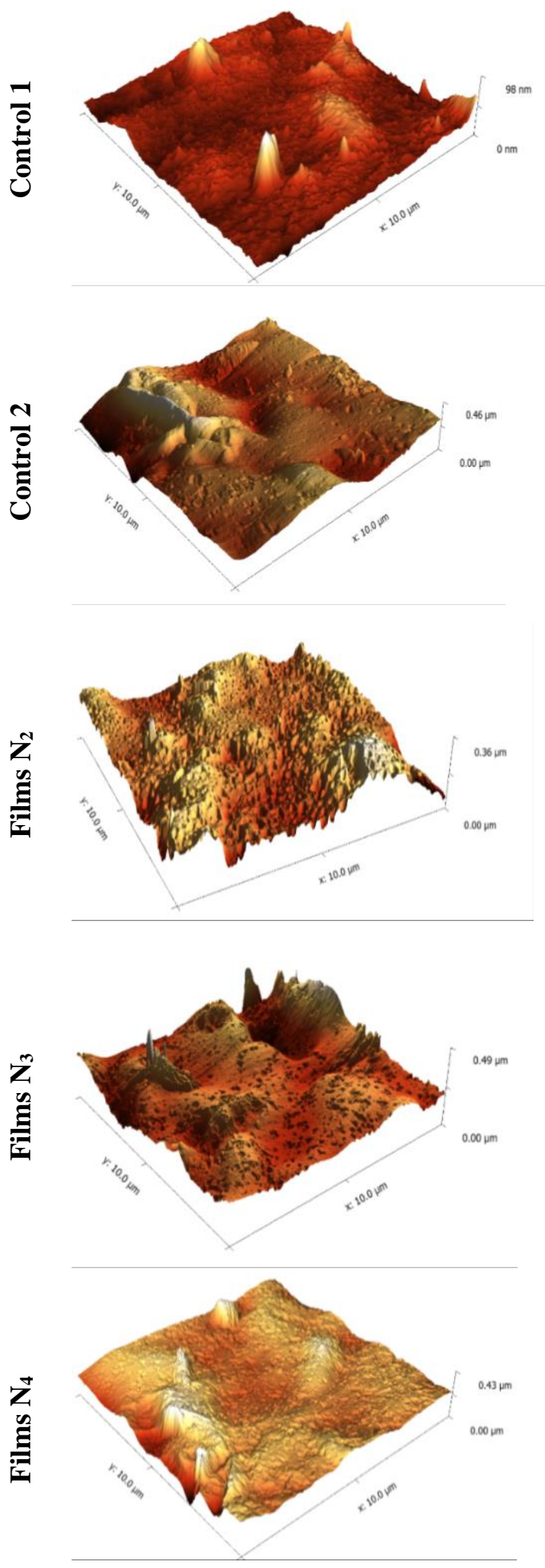

(b): 2D surface
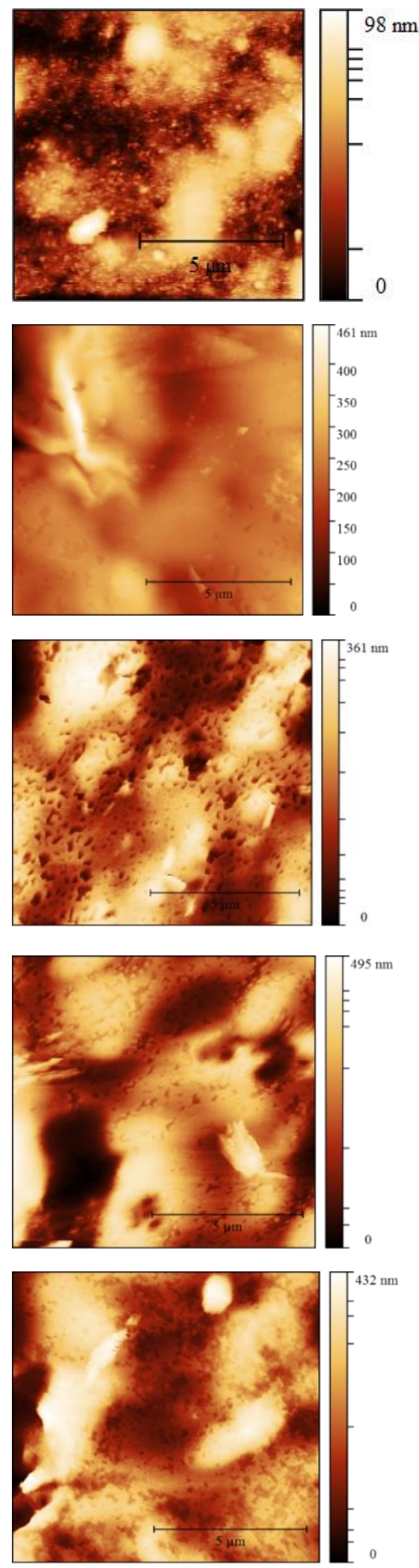

Figure 5. AFM micrographs of (a) 3D topography and (b) 2D surface of gelatin-chitosan films loaded with $\mathrm{O} / \mathrm{W}$ nanoemulsions containing encapsulated active compounds. $\mathrm{N}_{0}$ - Control 1: film without nanoemulsion; $\mathrm{N}_{1}$ - Control 2: film with control nanoemulsion (no encapsulated species); $\mathrm{N}_{2}$ : $\alpha$-tocopherol/cinnamaldehyde; $\mathrm{N}_{3}$ : $\alpha$-tocopherol/garlic oil; $\mathrm{N}_{4}$ : $\alpha$-tocopherol/cinnamaldehyde and garlic oil-loaded nanoemulsion. 

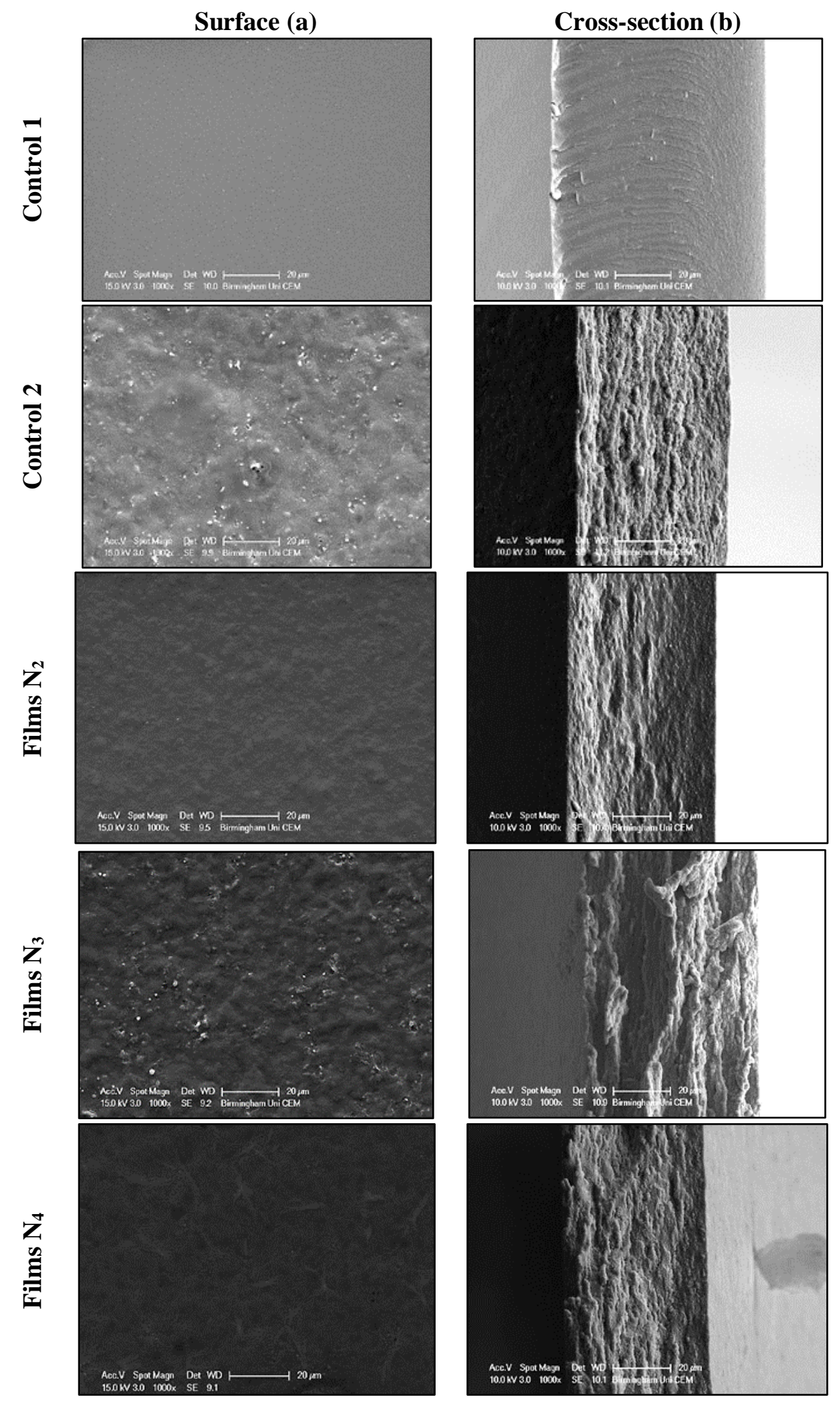

Figure 6. ESEM micrographs of the a) surface and b) cross section of gelatin-chitosan films loaded with $\mathrm{O} / \mathrm{W}$ nanoemulsions containing encapsulated active compounds. $\mathrm{N}_{0}$ - Control 1: film without nanoemulsion; $\mathrm{N}_{1}$ - Control 2: film with control nanoemulsion (no encapsulated species); $\mathrm{N}_{2}: \alpha$-tocopherol/cinnamaldehyde; $\mathrm{N}_{3}$ : $\alpha$-tocopherol/garlic oil; $\mathrm{N}_{4}: \alpha$-tocopherol/cinnamaldehyde and garlic oil-loaded nanoemulsion. 
Table 1. Encapsulation efficiencies of cinnamaldehyde, $\alpha$-tocopherol and garlic oil and mean droplet sizes, polydispersity indices (PDI), $\zeta$-potential and $\mathrm{pH}$ values of the $\mathrm{O} / \mathrm{W}$ nanoemulsions containing these encapsulated active compounds, as a function of storage time (all systems stored at $4 \pm 1^{\circ} \mathrm{C}$ ) .

\begin{tabular}{|c|c|c|c|c|c|c|c|c|}
\hline \multirow[b]{2}{*}{ Samples* } & \multirow{2}{*}{$\begin{array}{l}\text { Time } \\
\text { (Days) }\end{array}$} & \multicolumn{3}{|c|}{ Encapsulation efficiency } & \multirow{2}{*}{$\begin{array}{c}\text { Droplet size } \\
(\text { (nm) }\end{array}$} & \multirow[b]{2}{*}{ PDI } & \multirow{2}{*}{$\begin{array}{c}\zeta \text {-potential } \\
(\mathrm{mV})\end{array}$} & \multirow[b]{2}{*}{ pH } \\
\hline & & Cinnamaldehyde (\%) & $\alpha$-tocopherol(\%) & GO(\%) & & & & \\
\hline \multirow{4}{*}{$\begin{array}{l}\text { Control } \\
\left(N_{I}\right)\end{array}$} & 0 & ---- & --- & --- & $157.0 \pm 4.1^{\mathrm{aA}}$ & $0.19 \pm 0.02^{\mathrm{bA}}$ & $-17.3 \pm 0.6^{\mathrm{aA}}$ & $6.1 \pm 0.0^{\mathrm{abA}}$ \\
\hline & 30 & ---- & --- & ---- & $158.2 \pm 2.9^{\mathrm{aA}}$ & $0.20 \pm 0.02^{\mathrm{bA}}$ & $-16.0 \pm 1.4^{\mathrm{bA}}$ & $6.0 \pm 0.0^{\mathrm{bcA}}$ \\
\hline & 60 & ---- & --- & ---- & $161.2 \pm 5.9^{\mathrm{aA}}$ & $0.23 \pm 0.02^{\mathrm{aA}}$ & $-17.2 \pm 0.9^{\mathrm{abA}}$ & $6.1 \pm 0.0^{\mathrm{aA}}$ \\
\hline & 90 & ---- & --- & ---- & $156.9 \pm 4.7^{\mathrm{aA}}$ & $0.21 \pm 0.02^{\mathrm{bA}}$ & $-18.1 \pm 1.0^{\mathrm{aA}}$ & $6.0 \pm 0.0^{\mathrm{cA}}$ \\
\hline \multirow{4}{*}{$\begin{array}{c}\alpha-\mathrm{t} / \mathrm{Cin} \\
\left(N_{2}\right)\end{array}$} & 0 & $100 \pm 0.0^{\mathrm{aA}}$ & $57.1 \pm 1.1^{\mathrm{aA}}$ & $\begin{array}{c}--- \\
\end{array}$ & $123.1 \pm 1.5^{\mathrm{aB}}$ & $0.16 \pm 0.01^{\mathrm{aB}}$ & $-14.2 \pm 0.5^{\mathrm{aC}}$ & $5.3 \pm 0.0^{\mathrm{aD}}$ \\
\hline & 30 & ---- & --- & ---- & $121.5 \pm 0.6^{\mathrm{aC}}$ & $0.16 \pm 0.04^{\mathrm{aB}}$ & $-12.3 \pm 0.3^{\mathrm{bC}}$ & $5.1 \pm 0.0^{\mathrm{bC}}$ \\
\hline & 60 & ---- & --- & ---- & $121.9 \pm 2.7^{\mathrm{aC}}$ & $0.15 \pm 0.01^{\mathrm{aB}}$ & $-13.7 \pm 0.9^{\mathrm{aC}}$ & $4.7 \pm 0.1^{\mathrm{cC}}$ \\
\hline & 90 & $99.7 \pm 0.3^{\mathrm{aA}}$ & $46.6 \pm 0.4^{\mathrm{bB}}$ & & $122.4 \pm 2.5^{\mathrm{aC}}$ & $0.15 \pm 0.01^{\mathrm{aBC}}$ & $-13.7 \pm 1.0^{\mathrm{aC}}$ & $4.6 \pm 0.0^{\mathrm{dB}}$ \\
\hline \multirow{4}{*}{$\begin{array}{c}\alpha-\mathrm{t} / \mathrm{GO} \\
\left(N_{3}\right)\end{array}$} & 0 & ---- & $52.4 \pm 0.4^{\mathrm{aA}}$ & $92.2 \pm 1.9^{\mathrm{aA}}$ & $111.0 \pm 2.0^{\mathrm{aC}}$ & $0.16 \pm 0.0^{\mathrm{aB}}$ & $-15.9 \pm 0.7^{\mathrm{abB}}$ & $6.0 \pm 0.0^{\mathrm{aB}}$ \\
\hline & 30 & ---- & --- & --- & $112.5 \pm 2.4^{\mathrm{aD}}$ & $0.14 \pm 0.02^{\mathrm{aB}}$ & $-15.5 \pm 0.6^{\mathrm{abA}}$ & $5.4 \pm 0.0^{\mathrm{bB}}$ \\
\hline & 60 & ---- & --- & --- & $111.2 \pm 1.9^{\mathrm{aD}}$ & $0.14 \pm 0.01^{\mathrm{aB}}$ & $-16.0 \pm 0.8^{\mathrm{aB}}$ & $4.9 \pm 0.0^{\mathrm{cB}}$ \\
\hline & 90 & --- & $47.8 \pm 0.2^{\mathrm{bA}}$ & $88.5 \pm 2.7^{\mathrm{aA}}$ & $111.5 \pm 1.9^{\mathrm{aD}}$ & $0.14 \pm 0.01^{\mathrm{aC}}$ & $-15.0 \pm 0.9^{\mathrm{bB}}$ & $4.3 \pm 0.0^{\mathrm{dD}}$ \\
\hline \multirow{4}{*}{$\begin{array}{c}\alpha-\mathrm{t} / \mathrm{Cin} \\
\text { and GO } \\
\left(N_{4}\right)\end{array}$} & 0 & $93.9 \pm 2.6^{\mathrm{aA}}$ & $56.7 \pm 3.1^{\mathrm{aA}}$ & $70.9 \pm 2.0^{\mathrm{aB}}$ & $124.8 \pm 1.4^{\mathrm{bB}}$ & $0.15 \pm 0.01^{\mathrm{bB}}$ & $-14.4 \pm 0.7^{\mathrm{aC}}$ & $5.5 \pm 0.0^{\mathrm{aC}}$ \\
\hline & 30 & --- & --- & --- & $126.4 \pm 2.2^{\mathrm{bB}}$ & $0.16 \pm 0.02^{\mathrm{bB}}$ & $-13.7 \pm 0.4^{\mathrm{bB}}$ & $4.9 \pm 0.0^{\mathrm{bD}}$ \\
\hline & 60 & --- & --- & --- & $130.0 \pm 1.1^{\mathrm{aB}}$ & $0.20 \pm 0.01^{\mathrm{aC}}$ & $-13.8 \pm 0.5^{\mathrm{abC}}$ & $4.7 \pm 0.0^{\mathrm{cC}}$ \\
\hline & 90 & $89.6 \pm 0.6^{\mathrm{aB}}$ & $45.2 \pm 0.3^{\mathrm{bC}}$ & $61.6 \pm 0.1^{\mathrm{bB}}$ & $126.6 \pm 3.0^{\mathrm{bB}}$ & $0.16 \pm 0.02^{\mathrm{bB}}$ & $-14.5 \pm 0.6^{\mathrm{aBC}}$ & $4.5 \pm 0.0^{\mathrm{dC}}$ \\
\hline
\end{tabular}

Mean values \pm standard deviation $(\mathrm{n}=3$ ). Different lower case letters in the same column indicate significant differences $(\mathrm{p}<0.05)$ for the same sample over different days and different capital letters indicate significant differences $(\mathrm{p}<0.05)$ among different samples measured at the same time interval (day).

Cin: cinnamaldehyde; $\alpha$-t: $\alpha$-tocopherol; GO: garlic oil.

${ }^{*} N_{1}$ : Control nanoemulsion (no encapsulated species); $N_{2}$ : $\alpha$-tocopherol/cinnamaldehyde; $N_{3}: \alpha$-tocopherol/garlic oil; $N_{4}: \alpha$-tocopherol/cinnamaldehyde and garlic oil-loaded nanoemulsion. 
Table 2. Physical/Mechanical properties of gelatin-chitosan films loaded with $\mathrm{O} / \mathrm{W}$ nanoemulsions containing encapsulated active compounds.

\begin{tabular}{|c|c|c|c|c|c|c|c|}
\hline Sample * & $\begin{array}{c}\text { Thickness } \\
\text { (mm) }\end{array}$ & $\begin{array}{c}\text { Moisture } \\
\text { content }(\%)\end{array}$ & $\begin{array}{l}\text { Solubility in } \\
\text { water }(\%)\end{array}$ & $\begin{array}{l}\text { Swelling } \\
(\mathrm{g} / \mathrm{g})\end{array}$ & $\begin{array}{c}\text { TS } \\
(\mathbf{M P a})\end{array}$ & $\begin{array}{c}\text { EB } \\
(\%)\end{array}$ & $\begin{array}{c}\text { EM } \\
(\mathbf{M P a})\end{array}$ \\
\hline Films $N_{0}$ & $0.082 \pm 0.001^{\mathrm{a}}$ & $18.2 \pm 0.8^{\mathrm{a}}$ & $50.8 \pm 0.7^{\mathrm{a}}$ & $26.9 \pm 2.8^{b}$ & $19.0 \pm 2.1^{\mathrm{a}}$ & $89.1 \pm 6.4^{\mathrm{d}}$ & $101.4 \pm 4.5^{\mathrm{a}}$ \\
\hline Films $N_{l}$ & $0.081 \pm 0.002^{\mathrm{a}}$ & $17.8 \pm 1.8^{\mathrm{a}}$ & $47.5 \pm 0.6^{\mathrm{b}}$ & $30.6 \pm 0.6^{\mathrm{a}}$ & $10.0 \pm 1.1^{b c}$ & $123.3 \pm 1.3^{\mathrm{a}}$ & $29.0 \pm 3.6^{c}$ \\
\hline Films $\mathrm{N}_{2}$ & $0.081 \pm 0.002^{\mathrm{a}}$ & $18.2 \pm 1.8^{\mathrm{a}}$ & $44.0 \pm 2.1^{\mathrm{c}}$ & $27.4 \pm 2.5^{\mathrm{ab}}$ & $11.4 \pm 1.0^{\mathrm{b}}$ & $108.7 \pm 2.2^{c}$ & $37.3 \pm 2.5^{b}$ \\
\hline Films $\mathrm{N}_{3}$ & $0.081 \pm 0.002^{\mathrm{a}}$ & $17.3 \pm 2.1^{\mathrm{a}}$ & $43.1 \pm 2.3^{c}$ & $30.3 \pm 1.5^{\mathrm{a}}$ & $8.9 \pm 0.9^{c}$ & $111.7 \pm 4.8^{\mathrm{bc}}$ & $30.1 \pm 4.9^{c}$ \\
\hline Films $\mathrm{N}_{4}$ & $0.082 \pm 0.001^{\mathrm{a}}$ & $18.1 \pm 2.0^{\mathrm{a}}$ & $48.9 \pm 0.9^{\mathrm{ab}}$ & $25.3 \pm 0.8^{\mathrm{b}}$ & $9.8 \pm 3.7^{\mathrm{bc}}$ & $113.2 \pm 2.1^{\mathrm{b}}$ & $39.2 \pm 3.6^{\mathrm{b}}$ \\
\hline
\end{tabular}

Mean values \pm standard deviation $(\mathrm{n}=3)$. Different letters in the same column indicate significant differences $(\mathrm{p}<0.05)$.

* $N_{0}$ - Control 1: film without nanoemulsion; $N_{1}$ - Control 2: film with control nanoemulsion (no encapsulated species); $N_{2}: \alpha$-tocopherol/cinnamaldehyde; $N_{3}$ : $\alpha$-tocopherol/garlic oil; $N_{4}$ : $\alpha$-tocopherol/cinnamaldehyde and garlic oil-loaded nanoemulsion.

TS: Tensile strength; EB: Elongation at break; EM: Elastic modulus. 
Table 3. Light transmittance (\%) and transparency of gelatin-chitosan films loaded with O/W nanoemulsions containing encapsulated active compounds.

\begin{tabular}{|c|c|c|c|c|c|c|c|}
\hline \multirow[b]{3}{*}{ Sample* } & \multicolumn{6}{|c|}{ Light transmittance (\%) } & \multirow{3}{*}{$\begin{array}{c}\text { Transparency } \\
\text { value }\end{array}$} \\
\hline & \multicolumn{6}{|c|}{ Wavelength (nm) } & \\
\hline & 250 & 280 & 350 & 450 & 600 & 800 & \\
\hline Films $N_{0}$ & $22.2 \pm 0.3^{\mathrm{a}}$ & $23.9 \pm 0.6^{\mathrm{a}}$ & $80.0 \pm 0.4^{\mathrm{a}}$ & $90.9 \pm 0.2^{\mathrm{a}}$ & $94.7 \pm 0.2^{\mathrm{a}}$ & $97.6 \pm 0.2^{\mathrm{a}}$ & $0.29 \pm 0.01^{\mathrm{e}}$ \\
\hline Films $N_{1}$ & $5.0 \pm 0.7^{\mathrm{b}}$ & $9.6 \pm 0.3^{\mathrm{b}}$ & $66.3 \pm 0.7^{\mathrm{bc}}$ & $77.6 \pm 0.5^{\mathrm{d}}$ & $83.7 \pm 0.4^{\mathrm{d}}$ & $88.8 \pm 0.4^{\mathrm{e}}$ & $0.96 \pm 0.02^{\mathrm{a}}$ \\
\hline Films $\mathrm{N}_{2}$ & $0.0 \pm 0.0^{\mathrm{c}}$ & $0.1 \pm 0.0^{\mathrm{d}}$ & $63.7 \pm 1.4^{\mathrm{d}}$ & $85.7 \pm 0.6^{\mathrm{b}}$ & $91.4 \pm 0.4^{b}$ & $95.4 \pm 0.4^{b}$ & $0.48 \pm 0.02^{\mathrm{d}}$ \\
\hline Films $N_{3}$ & $0.1 \pm 0.0^{c}$ & $0.7 \pm 0.0^{c}$ & $67.5 \pm 1.7^{\mathrm{b}}$ & $83.8 \pm 1.7^{\mathrm{c}}$ & $87.7 \pm 1.4^{\mathrm{c}}$ & $91.2 \pm 1.4^{\mathrm{d}}$ & $0.71 \pm 0.09^{b}$ \\
\hline Films $N_{4}$ & $0.0 \pm 0.0^{\mathrm{c}}$ & $0.1 \pm 0.0^{\mathrm{d}}$ & $65.0 \pm 1.0^{\text {cd }}$ & $84.5 \pm 0.6^{\mathrm{bc}}$ & $88.9 \pm 0.5^{\mathrm{c}}$ & $92.5 \pm 0.6^{\mathrm{c}}$ & $0.63 \pm 0.03^{c}$ \\
\hline
\end{tabular}

Mean values \pm standard deviation $(\mathrm{n}=3)$. Different letters in the same column indicate significant differences $(\mathrm{p}<0.05)$.

$* N_{0}$ - Control 1: film without nanoemulsion; $N_{1}$ - Control 2: film with control nanoemulsion ( no encapsulated species); $N_{2}: \alpha$-tocopherol/cinnamaldehyde; $N_{3}$ : $\alpha$-tocopherol/garlic oil; $N_{4}$ : $\alpha$-tocopherol/cinnamaldehyde and garlic oil-loaded nanoemulsion. 
Table 4. Thermal properties and roughness characteristics of gelatin-chitosan films loaded with O/W nanoemulsions containing encapsulated active compounds.

\begin{tabular}{|c|c|c|c|c|c|c|}
\hline \multirow[b]{2}{*}{ Sample* } & \multicolumn{3}{|c|}{$1^{\text {st }}$ Scan } & \multirow{2}{*}{$\frac{2^{\text {nd }} \text { Scan }}{T_{\mathrm{g}}\left({ }^{\circ} \mathrm{C}\right)}$} & \multicolumn{2}{|c|}{ Roughness } \\
\hline & $\mathbf{T}_{\mathrm{g}}\left({ }^{\circ} \mathbf{C}\right)$ & $\Delta \mathbf{H}_{\mathrm{g}}(\mathrm{J} / \mathrm{g})$ & $\mathbf{T}_{\mathrm{m}}\left({ }^{\circ} \mathbf{C}\right)$ & & $\mathbf{R}_{\mathrm{a}}(\mathbf{n m})$ & $\mathbf{R}_{\mathbf{q}}(\mathbf{n m})$ \\
\hline Films $N_{0}$ & $45.6 \pm 0.6^{\mathrm{a}}$ & $12.1 \pm 0.8^{\mathrm{b}}$ & $54.9 \pm 0.8^{\mathrm{a}}$ & $8.6 \pm 2.2^{\mathrm{ab}}$ & 7.5 & 11.1 \\
\hline Films $N_{1}$ & $46.2 \pm 0.8^{\mathrm{a}}$ & $9.3 \pm 0.9^{\mathrm{a}}$ & $53.5 \pm 0.2^{\mathrm{a}}$ & $12.1 \pm 1.1^{\mathrm{a}}$ & 44.1 & 58.6 \\
\hline Films $\mathrm{N}_{2}$ & $45.5 \pm 0.4^{\mathrm{a}}$ & $9.0 \pm 0.2^{\mathrm{a}}$ & $54.4 \pm 0.2^{\mathrm{a}}$ & $8.2 \pm 2.7^{\mathrm{ab}}$ & 31.4 & 40.5 \\
\hline Films $N_{3}$ & $46.6 \pm 2.3^{\mathrm{a}}$ & $9.6 \pm 0.8^{\mathrm{a}}$ & $56.6 \pm 5.2^{\mathrm{a}}$ & $10.4 \pm 3.1^{\mathrm{ab}}$ & 39.5 & 53.9 \\
\hline Films $N_{4}$ & $45.6 \pm 0.4^{\mathrm{a}}$ & $9.3 \pm 0.5^{\mathrm{a}}$ & $54.6 \pm 0.2^{\mathrm{a}}$ & $6.7 \pm 1.4^{\mathrm{b}}$ & 32.3 & 42.6 \\
\hline
\end{tabular}

Mean values \pm standard deviation $(\mathrm{n}=3)$. Different letters in the same column indicate significant differences $(\mathrm{p}<0.05)$.

$* N_{0}$ - Control 1: film without nanoemulsion; $N_{1}$ - Control 2: film with control nanoemulsion (no encapsulated species); $N_{2}: \alpha$-tocopherol/cinnamaldehyde; $N_{3}$ : $\alpha$-tocopherol/garlic oil; $N_{4}$ : $\alpha$-tocopherol/cinnamaldehyde and garlic oil-loaded nanoemulsion.

$\mathrm{T}_{\mathrm{g}}$ : Glass transition temperature; $\mathrm{T}_{\mathrm{m}}$ : Melting temperature; $\Delta \mathrm{H}_{\mathrm{g}}$ : Melting enthalpy; $\mathrm{R}_{\mathrm{a}}$ : average roughness; $\mathrm{R}_{\mathrm{q}}$ : root-mean-square roughness. 
Table 5. Inhibition halos against P. aeruginosa and L. monocytogenes and Trolox Equivalent Antioxidant Capacity (TEAC) of gelatin-chitosan films loaded with $\mathrm{O} / \mathrm{W}$ nanoemulsions containing encapsulated active compounds.

\begin{tabular}{|c|c|c|c|c|c|}
\hline \multirow[t]{2}{*}{ Sample* } & \multicolumn{2}{|c|}{ Zone of inhibition $\left(\mathrm{mm}^{2}\right)$} & \multicolumn{3}{|c|}{$\begin{array}{c}\text { TEAC } \\
(\mu \mathrm{mol} \text { TE/g dried film })\end{array}$} \\
\hline & P. aeruginosa & L. monocytogenes & DPPH ${ }^{\bullet}$ method & ABTS $^{\bullet+}$ method & FRAP assay \\
\hline Films $N_{0}$ & $0.0 \pm 0.0^{\mathrm{c}}$ & $0.0 \pm 0.0^{\mathrm{a}}$ & $0.0 \pm 0.0^{c}$ & $0.0 \pm 0.0^{\mathrm{d}}$ & $6.9 \pm 0.4^{\mathrm{e}}$ \\
\hline Films $N_{l}$ & $0.0 \pm 0.0^{\mathrm{c}}$ & $0.0 \pm 0.0^{\mathrm{a}}$ & $0.0 \pm 0.0^{c}$ & $1.3 \pm 0.0^{c}$ & $39.8 \pm 0.2^{\mathrm{d}}$ \\
\hline Films $\mathrm{N}_{2}$ & $138.2 \pm 2.4^{\mathrm{a}}$ & $0.0 \pm 0.0^{\mathrm{a}}$ & $0.2 \pm 0.0^{\mathrm{a}}$ & $2.6 \pm 0.1^{\mathrm{a}}$ & $49.9 \pm 1.2^{c}$ \\
\hline Films $N_{3}$ & $138.2 \pm 0.0^{\mathrm{a}}$ & $0.0 \pm 0.0^{\mathrm{a}}$ & $0.1 \pm 0.0^{\mathrm{b}}$ & $2.5 \pm 0.0^{\mathrm{a}}$ & $81.5 \pm 2.2^{\mathrm{a}}$ \\
\hline Films $N_{4}$ & $65.4 \pm 1.4^{\mathrm{b}}$ & $0.0 \pm 0.0^{\mathrm{a}}$ & $0.1 \pm 0.0^{\mathrm{b}}$ & $2.3 \pm 0.1^{\mathrm{b}}$ & $68.3 \pm 2.9^{b}$ \\
\hline
\end{tabular}

Mean values \pm standard deviation $(\mathrm{n}=3)$. Different letters in the same column indicate significant differences $(\mathrm{p}<0.05)$.

$* N_{0}$ - Control 1: film without nanoemulsion; $N_{1}$ - Control 2: film with control nanoemulsion (no encapsulated species); $N_{2}: \alpha$-tocopherol/cinnamaldehyde; $N_{3}$ : $\alpha$-tocopherol/garlic oil; $N_{4}$ : $\alpha$-tocopherol/cinnamaldehyde and garlic oil-loaded nanoemulsion. 